\title{
?1
}

TI 2019-077/I

Tinbergen Institute Discussion Paper

\section{A behavioral decomposition of willingness to pay for health insurance}

\author{
Aurélien Baillon ${ }^{1}$ \\ Aleli Kraft ${ }^{2}$ \\ Owen O'Donnell ${ }^{1}$ \\ Kim van Wilgenburg ${ }^{3}$
}

${ }^{1}$ Erasmus School of Economics, Erasmus University Rotterdam, Tinbergen Institute

2 School of Economics, University of the Philippines Diliman

${ }^{3}$ Erasmus School of Health Policy and Management, Erasmus University Rotterdam 
Tinbergen Institute is the graduate school and research institute in economics of Erasmus University Rotterdam, the University of Amsterdam and VU University Amsterdam.

Contact: discussionpapers@tinbergen.nl

More TI discussion papers can be downloaded at https://www.tinbergen.nl

Tinbergen Institute has two locations:

Tinbergen Institute Amsterdam

Gustav Mahlerplein 117

1082 MS Amsterdam

The Netherlands

Tel.: +31(0)205984580

Tinbergen Institute Rotterdam

Burg. Oudlaan 50

3062 PA Rotterdam

The Netherlands

Tel.: +31(0)10408 8900 


\title{
A behavioral decomposition of willingness to pay for health insurance
}

\author{
Aurélien Baillon, Aleli Kraft, Owen O'Donnell, Kim van Wilgenburg ${ }^{\dagger}$
}

September 6, 2019

\begin{abstract}
Despite widespread exposure to substantial medical expenditure risk in low-income populations, health insurance enrollment is typically low. This is puzzling from the perspective of expected utility theory. To help explain it, this paper introduces a decomposition of the stated willingness to pay (WTP) for insurance into its fair price and three behavioral deviations from that price due to risk perception and risk attitude consistent with prospect theory, plus a residual. To apply this approach, we elicit WTP, subjective distributions of medical expenditures and risk attitude (utility curvature and probability weighting) from Filipino households in a nationwide survey. We find that the mean stated WTP of the uninsured is less than both the actuarially fair price and the subsidized price at which public insurance is offered. This is not explained by downwardly biased beliefs: both the mean and the median subjective expectation are greater than the subsidized price. Convex utility in the domain of losses pushes mean WTP below the fair price and the subsidized price, and the transformation of probabilities into decision weights depresses the mean further, at least using one of two specific decompositions. WTP is reduced further by factors other than risk perception and attitude.
\end{abstract}

JEL Classification: D84, I13

Keywords: Health insurance, willingness to pay, subjective probability, prospect theory, medical expense

Acknowledgements: We thank Pierre Koning, Menno Pradhan, Peter Wakker and participants at various seminars and conferences for comments. We are grateful to the World Bank for funding the Daisy III survey and especially Caryn Bredenkamp for the opportunity to collect the data on risk perception and attitude as part of this survey. The research of Aurelien Baillon is made possible by a Vidi grant of the Netherlands Organization for Scientific Research. Owen O'Donnell is supported by the Swiss Agency for Development and Cooperation / National Science Foundation Programme for Research on Global Issues for Development through the grant, "Inclusive social protection for chronic health problems" (400640_160374, PI: Jürgen Maurer).

† Baillon: Erasmus School of Economics, Erasmus University Rotterdam, Tinbergen Institute baillon@ese.eur.nl; Kraft: School of Economics, University of the Philippines Diliman, alelik@yahoo.com; O’Donnell: Erasmus School of Economics, Erasmus University Rotterdam, Tinbergen Institute, Faculty of Economics and Business, University of Lausanne odonnell@ese.eur.nl; van Wilgenburg: Erasmus School of Health Policy and Management, Erasmus University Rotterdam vanwilgenburg@eshpm.eur.nl 


\section{Introduction}

Despite widespread exposure to risks of substantial medical expenses in low- and middle-income countries, demand for health insurance is often low. Many of those not covered through mandatory insurance for salaried employees or fully subsidized insurance for the poor do not voluntarily insure, even at highly subsidized premiums (Thornton et al 2010; Acharya et al. 2013; Banerjee et al 2014; Bredenkamp et al. 2015; Capuno et al 2016; Pettigrew and Mathauer 2016; Wagstaff et al 2016; Assuming et al 2017; Chemin 2018). In the US, take-up of subsidized health insurance by low-income households has also been far from complete (Currie and Gruber 1996; Chernew et al 1997; Bundorf and Pauly 2005; Levy and DeLiere 2008). This low demand does not square with estimates of large welfare gains from insuring low-income populations that are obtained under assumptions that individuals (i) have accurate perception of their medical expenditure risks and (ii) are risk averse (Pauly et al. 2009; Gross and Notowidigdo 2011; Shigeioki 2014; Limwattananon et al 2015; Barnes et al 2017; Finkelstein et al 2018). The apparent inconsistency has two possible causes. One is that many misperceive the risks. The other is that not insuring is the best option given risk attitude, which differs from the ubiquitous risk aversion assumed to estimate the gains from insurance. For instance, individuals may have convex utility for some outcomes and they may weight probability as in prospect theory. Distinguishing the influence of risk perception from that of risk attitude on insurance demand is obviously critical to making an appropriate policy response to the low take-up of health insurance in low-income settings.

This paper aims to help explain the low demand by introducing a new decomposition of the stated willingness to pay (WTP) for insurance into its fair price and three behavioral deviations from that price that arise from subjective beliefs about the distribution of medical expenses and two dimensions of risk attitude consistent with prospect theory. A residual term absorbs all influences on WTP that are not captured by the behavioral model, such as informal insurance options and the perceived quality of the insurance and the healthcare it covers. The method quantifies the contributions of risk perception and risk attitude to the low observed demand for insurance relative to all other potential determinants of WTP. It can allow those who wish to encourage insurance take-up to assess whether to focus their efforts on correcting misperceptions of risk, influencing risk attitude or unpacking WTP further to identify perceived deficiencies in the insurance product and informal ways of coping with risk that drive down the demand. In addition to health insurance, the decomposition could be used to understand what contributes to the low demand for (subsidized) weather and crop insurance in lowincome settings (e.g. Giné et al, 2008; Cole et al, 2013) and, indeed, any insurance product.

The fair price of insurance - the mathematical expectation of the loss - is estimated by mean spending on medical care within a risk pool. The perceived fair price is derived from elicited beliefs about future spending that are used to estimate each individual's subjective distribution of medical

expenses. The deviation of the perceived fair price from the objective benchmark gives the contribution of beliefs to the WTP. This allows us to evaluate the validity of the often-posed, but seldom-tested, 
hypothesis that misperceptions of risk are responsible for anomalies in the demand for insurance (Viscusi 1995). At the individual level, the perceived fair price can differ from the estimated fair price due to within group heterogeneity in healthcare needs that is recognized by the individual - private information. However, in aggregate, any discrepancy between the mean perceived fair price and the fair price indicates systematically biased beliefs, which can be either optimistic or pessimistic. The contributions of two dimensions of risk attitude - utility curvature and probability weighting - are identified by eliciting the parameters using hypothetical lotteries that are designed to be feasible in a large field survey of individuals with low educational attainment. The residual is the difference between the directly elicited WTP and that derived indirectly from feeding the subjective probability and risk attitude data into the behavioral model. Quantification of this residual allows us to compare the contributions that the risk perceptions and risk attitude make to the low demand for insurance in comparison with the aggregate contribution of all other factors.

We obtain all the data required for the decomposition - actual medical expenses, elicited beliefs about future medical expenses, risk attitudes and the stated WTP - from a nationwide household survey conducted in the Philippines. The sample includes households with and without health insurance. Our focus is on estimating and decomposing the WTP of the uninsured in order to evaluate potential explanations for their decision not to insure. For the insured, we decompose WTP for supplementary insurance that would cover expenses not currently reimbursed.

Our approach to deriving WTP for insurance from a model differs from that usually followed both in the method used to estimate risk exposure and in the assumptions about preferences used to evaluate the impact of risk on welfare. Estimation of exposure to medical expenditure risk is commonly based on the cross-sectional distribution of those expenditures (e.g. Limwattananon et al 2015). But only under a strong assumption is the cross-section distribution indicative of the risk of volatile medical expenses faced by any individual. ${ }^{1}$ And even if this assumption holds, still more are required: people must have access to information on the cross-sectional distribution and they must use it to form rational expectations about the risks they face (Manski 2004). We relax these assumptions by eliciting beliefs about future medical expenses and using them to gain insight into perceptions of the value of insurance. While a sizeable literature has explored a multitude of reasons for low insurance demand in low-income settings (Platteau et al 2017), empirical investigation of the role of risk perception is rare. ${ }^{2}$ We know of only two previous studies - both in East Africa - that have used elicited subjective probabilities of

\footnotetext{
${ }^{1}$ The assumption is that medical expenditures are generated by a stationary ergodic process: they are identically and independently distributed across both time and (observationally equivalent) households.

${ }^{2}$ One exception is that simulated experience of disaster was found to have a substantial positive impact on Chinese farmers' take-up of weather insurance (Cai and Song 2017). Altered risk perception is the obvious channel. Although no effect was found on the reported subjective probability of disaster, simply informing farmers of the objective probability of an extreme weather event increased enrollment by three times as much as the simulated exposure to such a disaster.
} 
incurring medical expenses (Dercon et al 2015; Yilma et al 2018). ${ }^{3}$ Both find signs of pessimism bias - the sample mean of the subjective expectations exceeds the mean of realized (or past) medical spending. This pessimism is inconsistent with low demand for insurance. However, unlike this paper, neither study isolates the contribution of risk perception to the valuation of insurance. ${ }^{4}$

Our second departure from the standard approach to deriving WTP is to allow insurance behavior to deviate from that characterized by the expected utility (EU) model. Prospect theory (PT), the most popular model of choice under risk, assumes that people maximize utility defined over changes in wealth with respect to a reference point (Kahneman and Tversky 1979; Tversky and Kahneman 1992). If the reference is the state in which insurance is not purchased and medical expense is not incurred, which is consistent with the standard status quo definition of the reference point and previous application of PT to insurance (Wakker et al 1997), then the insurance decision is taken by comparing outcomes entirely in the loss domain, where estimates tend to find the PT value function over wealth changes is convex, implying risk seeking. This would reduce WTP for insurance and may contribute to the low demand observed in low-income populations. It may partly account for the discrepancy between the low revealed preference for insurance and the large welfare gains predicted from an EU model with risk aversion represented solely by utility that is concave in the level of wealth.

Under PT with a no insurance-no loss reference point, if there is positive demand for insurance, then it arises from transformation of probabilities into decision weights that display limited discrimination between likelihood levels and result in overweighting of low probability, high loss scenarios. There is evidence from a high-income setting that insurance demand is influenced by the nonlinear evaluation of probabilities more than it is by the nonlinear evaluation of outcomes, which is the sole source of risk aversion under EU. Using revealed preferences for home and auto insurance deductibles in the US, Sydnor (2010) and Barseghyan et al. (2013) find that overweighting of small probabilities likely contributes to overinsurance. However, without data on subjective probabilities, these studies are not able to discriminate between the distortion of accurately perceived risks and the misperception of risks. ${ }^{5}$ We are able to do this because we elicit both subjective probabilities and probability weighting, the combination of which allow us to determine decision weights as in the model of Tversky and Fox (1995). And we use these to explain the valuation of insurance in a low-income

\footnotetext{
${ }^{3}$ Subjective probabilities of medical expenses have been elicited in some waves of the US Health and Retirement Study but we are not aware of any study that has made use of these data.

${ }^{4}$ Yilma et al (2018) find that subjective expectations of medical expenses are not associated with health insurance enrollment in Ethiopia, although respondents who perceive greater volatility in their future expenses are more likely to report an intention to insure.

${ }^{5}$ To be fair, Sydnor (2010) argues convincingly that risk misperception would have to be severe to explain the choices observed in his data. He also argues, on the basis of back-of-the-envelope calculations, that loss aversion of the Köszegi and Rabin $(2006,2007)$ type likely influences these choices more than probability weighting alone. We discuss loss aversion in sections 2 and 7.
} 
setting in which there appears to be underinsurance, rather than examining the choice of deductible in a high-income setting where there is overinsurance.

We separate the difference between the directly reported WTP for insurance and the fair price - the risk premium - into four components. First, we define the belief premium as the difference between the perceived fair price based on subjective assessment of medical expenditure risk and the fair price based on the empirical distribution of expenditures. Second, we incorporate PT utility over losses and compute the WTP for insurance based on each individual's elicited utility curvature and their beliefs about the distribution of medical expenses they face. We call the difference between this computed WTP and the perceived fair price the utility premium; it captures the impact of utility curvature applied to the perceived dispersion of potential losses. If utility is indeed convex over losses, this will push down WTP and help explain low demand for insurance. Then we add (elicited) probability weighting to the model and re-compute WTP. The change in value gives what we call the weighting premium. If the loss were binary and small in probability, and if there were overweighting of small probabilities, then this premium would be positive. It would raise WTP. This is the scenario that has been considered in previous attempts to use PT to understand insurance demand (Wakker et al 1997; Schmidt 2016). ${ }^{6}$ But medical expense is a continuously distributed loss. Overweighting of small probabilities could result in excessive response to both unusually high and unusually low expenses. The sign of the weighting premium is, therefore, difficult to predict for a non-binary loss. Finally, we take the WTP stated by the respondent and subtract the WTP derived by entering their elicited subjective probabilities and both risk attitude parameters into our complete behavioral model to get a residual that captures all influences on the (stated) value of insurance that the model does not explain.

In a theoretical paper, Hilton (1988) splits the risk premium under PT into the contributions of utility curvature and probability weighting. No explicit allowance is made for risk misperception. If the probability weighting function applied to objective probabilities is viewed as capturing both the perception of probabilities and the transformation of those perceptions into decision weights, then the influence of risk perception would enter the probability weighting premium in Hilton's decomposition. We separate out this contribution to the risk premium. Further, using information on stated WTP - not only model-derived WTP - we show how to decompose the premium further to identify the contribution of factors other than risk perception and attitude.

We elicit subjective beliefs using visual aids (Delavande et al. 2011b). Respondents are given 10 sticks and asked to distribute them across four cups representing different intervals of medical expenses in accordance with how likely they are to spend in each interval. The responses along with a

\footnotetext{
${ }^{6}$ Barseghyan et al. (2013) use rank-dependent utility (RDU) to examine the influence of probability weighting on the choice of insurance deductible. Since there is full reimbursement of losses in excess of the deductible, there are only two states to consider - claim (with small probability) and incur the deductible, or do not claim. Overweighting of small probabilities results in demand for a lower deductible.
} 
distributional assumption allows us to estimate the first two moments of the subjective distribution of medical expenses for each household. We show that the elicited beliefs correlate with predictors of medical expenditure, including past spending, although without data on future spending we are not able to assess forecast accuracy directly. To elicit risk attitudes, we design and implement a method that can identify sophisticated preference parameters under PT and yet is comprehensible for less educated respondents interviewed in a field survey, as opposed to the laboratory environment in which risk attitudes are often obtained.

We find that the mean WTP stated by the uninsured is only about two thirds of the fair price for the average risk, and it is also less than the subsidized premium at which they are offered (but decline) insurance. Thus, despite the recognized vulnerability of stated WTP to hypothetical bias that tends to result in overstatement of true willingness to pay for a private good (Murphy et al 2005), we obtain stated preferences that are consistent with revealed preferences. There are three main findings from decomposition of the WTP of the uninsured. First, the low mean stated WTP cannot be explained by the belief premium, the mean of which is close to zero, indicating that, on average, misperception of risk does not explain the decision not to insure. The mean subjectively expected medical expenditure is approximately equal to the objective expectation, and it is greater than the subsidized premium at which insurance is offered. The median subjective expectation is also greater than the price at which insurance is offered. Hence, for most of the uninsured, beliefs do not explain their decision not to insure.

Second, risk attitudes explain a large part of shortfall of mean stated WTP from the fair price. There is an absolutely large negative utility premium, which comes from risk seeking in the domain of losses. More surprisingly, probability weighting reduces WTP for insurance, on average. This is the net effect of overweighting small probabilities of both high and low medical expenses. However, at the median, probability weighting makes no contribution to WTP.

The behavioral model is nonlinear and so the decomposition is path dependent; results can depend on the order in which the components are identified. The first logical step is to identify what people believe would be fair to pay by replacing frequencies with beliefs to obtain the subjectively fair price. Moreover, since decision weights are applied to beliefs, it is logical to identify the contribution of beliefs to WTP prior to determining the role played by probability weighting. The order in which to identify the contributions of utility curvature and probability weighting is less obvious. Our findings are mostly robust to reversing the order by first applying nonlinear weighting to linear utility to identify the contribution of the decision weights, and then replacing linear utility with PT utility in losses to identify the contribution of utility curvature. Taking this approach, the latter contribution is even more negative, reducing WTP to an even greater extent at the mean. The mean contribution of probability 
weighting is no longer negative, however. ${ }^{7}$ We present results from both orders separately but an alternative approach is to rely on the average over the two. ${ }^{8}$ Irrespective of the order of identification, risk attitudes, mainly through convex utility over losses, push WTP below the fair price.

Finally, we find a negative mean residual: on average, stated WTP is less than the model predicts. This unexplained low demand for formal insurance may be due to informal and self insurance options available to households (Townsend 1994; Gollier 2003; Giesbert et al 2011). Other factors that potentially depress demand, are not captured by our model and so enter the residual if they influence the stated WTP include poor understanding of the insurance concept (Platteau 1997; Basaza et al 2008), perceived low quality of the medical providers the insurance covers (De Allegri et al 2006; Basaza et al 2008), liquidity constraints (Giné et al 2008; Cole et al 2013; Liu and Myers 2016), time preference (Casaburi and Willis 2018; van Wilgenburg et al 2018), lack of trust in the insurance product (Giné et al 2008; Cole et al 2013; Cai et al 2015; Dercon et al 2015; Chemin 2018) - particularly in the presence of ambiguity aversion (Elabed and Carter 2015; Bryan 2018) - and, related to this, default risk (Doherty and Schlesinger 1990; Wakker et al 1997; Liu and Myers 2016). ${ }^{9}$ We establish that these extraneous factors, in aggregate, contribute half as much to the deficit of WTP from the fair price as does risk attitude, on average.

We find that, on average, the insured have no demand for actuarially fair supplementary insurance to cover expenses that are not reimbursed by the insurance currently held. Their mean stated WTP is less than the mean of such expenses. Again, this is not explained by misperception of the risks. The mean belief premium is positive: subjective expectations exceed objective expectations. The mean fair price and perceived fair price are both higher for the voluntarily insured than they are for the uninsured. Given that these prices are calculated from out-of-pocket spending only and the insured have additional reimbursed expenses, this indicates that the higher risks do enroll voluntarily. There is adverse selection. The low WTP for supplementary insurance is explained by risk attitudes - both convex utility over losses and probability weighting - and residual factors.

Section 2 explains how we decompose WTP. Section 3 provides background on health insurance in the Philippines. Section 4 presents the data and methods we use to obtain the parameters needed to estimate the components of the decomposition. Section 5 assesses the validity of the elicited beliefs and section 6 presents the results of the decomposition. Section 7 discusses the interpretation of

\footnotetext{
${ }^{7}$ The median contributions of both utility curvature and probability weighting are insensitive to the order of identification.

8 This is also the Shapley value of each component.

${ }^{9}$ Platteau et al (2017) review the literature that seeks to explain low demand for microinsurance against health and agricultural risks in low-income countries. Our application is to nationwide, public health insurance.
} 
the results and their robustness, as well as limitations of the method and possible extensions to it. The final section concludes.

\section{Decomposition of willingness to pay}

Within a period of time spanning the length of an insurance contract, many do not incur medical expenses. Others experience extremely large expenses. We model the distribution of medical expenses faced by an individual by a probability mass at 0 and a density over non-zero expenses. Let $p_{0}$ be the probability of zero expense and $f$ be the density conditional on incurring any expense. Both $p_{0}$ and $f$ vary with observable predictors of medical needs and access to healthcare facilities. Conditional on these observables, the negative of the actuarially fair price for full health insurance is:

$$
-\mu=\left(1-p_{0}\right) \int_{-\max }^{0} x f(x) d x
$$

where $x$ represents (negative) values of medical expenses and $\max$ is the maximum possible expense. We work with negative values to simplify expressions for WTP presented below. Under EU, the willingness to pay for full health insurance $\left(W T P_{E U}\right)$ is the payment that achieves the certainty equivalent of expected utility without insurance:

$$
U\left(W-W T P_{E U}\right)=p_{0} U(W)+\left(1-p_{0}\right) \int_{-\max }^{0} U(W+x) f(x) d x,
$$

where $W$ is wealth.

The difference between $W T P_{E U}$ and the expected medical expense $(\mu)$ is the standard risk premium, which is positive if and only if $U$ is concave. The prediction of positive demand for insurance at an actuarially fair premium is inconsistent with low enrollment in subsidized voluntary health insurance programs (Thornton et al 2010; Acharya et al. 2013; Bredenkamp et al. 2015; Capuno et al 2016; Pettigrew and Mathauer 2016; Wagstaff et al 2016; Assuming et al 2017; Chemin 2018).

There are several reasons why an individual's WTP may differ from that predicted by the EU model applied to their risk estimated from the observed distribution of medical expenditures over individuals with similar characteristics. First, private information about their health, as well as their

proneness to optimism or pessimism, may cause their beliefs to deviate from this estimated risk. Assume we can model beliefs by probabilities and let $p_{0}^{s}$ and $f^{s}$ be the subjective equivalents of $p_{0}$ and $f$ respectively. Substituting $p_{0}^{s}$ and $f^{s}$ for their objective counterparts in Eq. 1 gives the perceived fair price of full insurance $\left(\mu^{s}\right)$. We call the difference between this and the fair price based on observable characteristics the belief premium $\left(\pi^{b}=\mu^{s}-\mu\right)$. This can be positive or negative, depending on the agent's private information and degree of optimism. 
Second, behavior may deviate from EU maximisation. Under PT (Kahneman and Tversky, 1979), utility is maximized not over final wealth but over changes in wealth with respect to a reference point. Let $u$ be the PT value function, with $u(0)=0$. It is concave for gains but convex for losses (implying risk seeking in the latter domain), and it is steeper for losses than for gains (loss aversion). The reference point is typically assumed to be the status quo. Applied to the insurance decision, this has been defined as the state in which insurance is not purchased and the loss is not incurred (Wakker et al., 1997). ${ }^{10}$ We are then only concerned with the loss domain and loss aversion is irrelevant. ${ }^{11}$ With this representation of preferences and using the subjective distribution of medical expenses, WTP is determined by:

$$
\begin{aligned}
u\left(-W T P_{u}\right) & =p_{0}^{s} u(0)+\left(1-p_{0}^{s}\right) \int_{-\max }^{0} u(x) f^{s}(x) d x \\
& =\left(1-p_{0}^{s}\right) \int_{-\max }^{0} u(x) f^{s}(x) d x .
\end{aligned}
$$

We call the difference between $W_{u}$ and the perceived fair price the utility premium $\left(\pi^{u}=W T P_{u}-\mu^{s}\right)$.

This is negative for people with convex utility in the loss domain, which is typically observed. Hence, it can potentially contribute to low WTP.

According to PT, the second way in which behavior can deviate from EU, and so WTP differ from $W T P_{E U}$, is through the transformation of probabilities into decision weights. We use Tversky and Kahneman's (1992) cumulative PT, in which the cumulative probabilities are transformed. ${ }^{12}$ Let $F^{s}$ be the cumulative distribution function associated with $f^{s}$. The subjective probability of incurring expenditure greater than $-x$ is $\left(1-p_{0}^{s}\right) F^{s}(x) \cdot{ }^{13}$ In cumulative PT, this (cumulative) probability is

\footnotetext{
${ }^{10}$ In a model with a binary loss and no probability weighting, Schmidt (2016) allows the status quo to be state dependent. It corresponds to having no insurance and either incurring the loss or not. With this set up, there can be gains, e.g. insurance is purchased and the loss is incurred, as well as losses. The model yields predictions only when Tversky and Kahneman's (1992) specific value function is imposed. With decreasing sensitivity to both gains and losses, and with loss aversion, either full insurance or no insurance is demanded. The probability of insuring increases with the loss probability. In fact, at plausible parameter values, insurance would only be taken at very high loss probabilities $(>0.7)$. Schmidt shows that a model in which final wealth under full insurance is taken as the reference point yields more credible results. Under the same assumptions made with the state dependent reference point, the outcome is again either full insurance or no insurance. However, now insurance is purchased for all but very low loss probabilities, given plausible value function parameter values.

${ }^{11}$ Drawing on the idea that a sense of loss arises from a surprise event but not a purchase (Novemsky and Kahneman 2005; Köszegi and Rabin 2006, 2007), Sydnor (2010) argues that loss aversion can influence the demand for insurance. Indeed, he suggests this is a possible explanation for revealed preference for expensive low-deductible insurance plans that are consistent with the EU model only with implausibly high degrees of risk aversion. We do not elicit loss aversion and so cannot incorporate this into our behavioral decomposition. In the concluding section, we argue that the Köszegi and Rabin model does not help explain low demand for insurance.

12 The original version of PT can lead to violations of stochastic dominance (see Wakker (2010, Appendix 9.8)) and is not applicable to prospects with continuous distributions, such as medical expenses.

${ }^{13}$ Keep in mind that $x$ is the negative valued loss corresponding to expenditure of $-x$.
} 
transformed through a weighting function, $w$. The derivative of the probability, the density $\left(1-p_{0}^{s}\right) f^{s}(x)$, must be replaced in Eq. 3 by the derivative of $w\left(\left(1-p_{0}^{s}\right) F^{s}(x)\right)$, that is $\left(1-p_{0}^{s}\right) f^{s}(x) w^{\prime}\left(\left(1-p_{0}^{s}\right) F^{s}(x)\right)$. This gives,

$$
u\left(-W T P_{P T}\right)=\left(1-p_{0}^{s}\right) \int_{-\max }^{0} u(x) f^{s}(x) w^{\prime}\left(\left(1-p_{0}^{s}\right) F^{s}(x)\right) d x
$$

We call the difference between $W T P_{P T}$ and $W T P_{u}$, which captures the impact of probability weighting, the weighting premium $\left(\pi^{w}=W T P_{P T}-W T P_{u}\right)$.

The sign of weighting premium depends on a combination of factors. The function $w$ has been found to be typically inverse-S shaped, i.e., overweighting small probabilities (below 1/3 or so) and underweighting large ones. Then, in the case of a binary prospect with a small probability of bearing a fixed amount of expenditure as opposed to incurring no expenditure, probability weighting will increase the WTP and the weighting premium will be positive. For losses that are not binary, the implication of the transformation of probabilities into decision weights is less obvious. The derivative of an inverse-S weighting function $-w^{\prime}$ in Eq. $4-$ is larger than 1 for both low and high values of the cumulative distribution, and is smaller than 1 for intermediary values. Hence, the probability of extreme outcomes in both directions (expenses close to max but also 0) will be overweighted, while the intermediary expenses will be underweighted. The global impact of $w$ thus depends on the whole distribution of expenses perceived by the individual, as well as the shape of their weighting function.

Finally, the WTP given by Eq. 4 can be compared with the WTP for full insurance reported by the individual through a direct elicitation task $\left(W T P_{R}\right)$ to get a residual $\left(\pi^{\varepsilon}=W T P_{R}-W T P_{P T}\right)$. This includes everything that influences the individual's reported valuation of insurance that is not captured by our model. That is, everything besides risk perception and risk attitude.

An alternative risk premium equal to the difference between an individual's reported WTP and the fair price of insurance based on their observable risk characteristics can be written as the sum of the three premiums defined by the behavioral model, plus the residual,

$$
W T P_{R}-\mu=\pi^{b}+\pi^{u}+\pi^{w}+\pi^{\varepsilon} .
$$

Under the assumption that stated WTP corresponds to true WTP, the left hand side gives the perceived gain from insuring at a premium that is actuarially fair for the average risk. The signs of the premiums on the right hand side cannot be predicted a priori because they depend on beliefs and private information. An exception is the utility premium, $\pi^{u}$, which will be negative if, consistent with PT, utility is convex in the domain of losses. Figure 1 displays the case of an individual who a) expects to spend less than is predicted on the basis of their observable characteristics $\left(\pi^{\mathrm{b}}<0\right)$, which may be due to optimism or private information that they are in better than average health, $b$ ) has a convex PT value 
function over for losses $\left(\pi^{\mathrm{u}}<0\right)$, c) displays inflated sensitivity to (possibly low) probabilities of higher medical expenses resulting in a positive weighting premium $\left(\pi^{\mathrm{w}}>0\right)$, and $\left.\mathrm{d}\right)$ perceives and states a lower WTP due to influences other than the modelled risk perceptions and risk attitudes $\left(\pi^{\varepsilon}<0\right)$.

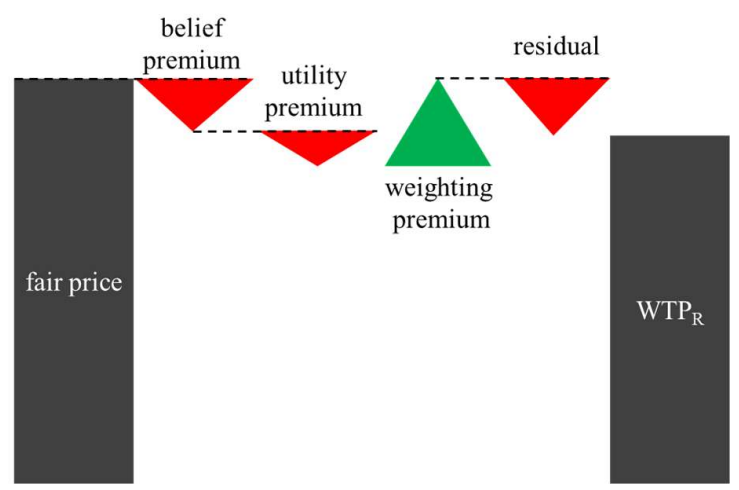

Figure 1. Behavioral decomposition of WTP

In fact, for the average uninsured individual in our sample, who, consistent with not being insured, states a WTP below the actuarially fair and subsidized prices, all the premiums turn out to be negative except the belief premium. While there is much heterogeneity, on average, these individuals have approximately unbiased beliefs and they display insensitivity to probabilities of high medical expenses.

Determination of the signs and relative magnitudes of the four sources of difference between the reported WTP and the fair price throws light on the perceived welfare gain from insurance and can potentially help identify broad strategies to influence insurance uptake. Given the average belief premium is close to zero, communicating information on the objective expectation of medical expenses would not raise the demand for fair-priced insurance. It may well do the opposite. The negative utility premium suggests that demand may remain low as long as the reference point is such that the choice is viewed as one over prospects that lie exclusively in the loss domain. If the choice could be framed to shift the reference point and bring gains as well as losses into play, then loss aversion would help offset the reduction in WTP arising from convexity in the loss domain (Sydnor 2010; Schmidt 2016). The negative weighting premium suggests that while expectations are unbiased, there is overweighting of the chance of having low medical expenses or avoiding them entirely. Finally, the negative residual can result from a number of factors, other than risk perceptions and preferences, that have been identified as potentially contributing to the low demand for health, and farming, insurance in low-income settings (Platteau et al 2017).

We noted in the introduction that the nonlinearity of the behavioral model renders the decomposition path dependent. It makes sense to start with beliefs, to obtain what people believe would be a fair price. Furthermore, since the weighting function is applied to beliefs, it is logical to identify the contribution of beliefs prior to that of decision weights. The residual contribution is a remainder and is necessarily 
computed last. That leaves the order of identification the utility curvature and probability weighting contributions to be decided. The order used above has the advantage of identifying the weighting contribution as the shift in WTP that would be observed if subjective probabilities were no longer distorted when forming decision weights, while utility curvature, as well as beliefs, remained unaltered. But one could argue for setting beliefs and decision weights to their observed, elicited values, and then identifying the contribution of utility curvature as the change in WTP on moving from linear to nonlinear utility. This is the approach taken by Hilton (1988), although he does acknowledge the alternative method we present above. Since one decomposition is not unambiguously more logical than the other, we present results from both. Specifically, the alternative decomposition involves first applying the probability weighting function to linear utility, calculating the certainty equivalent and subtracting the subjective expectation to get the weighting premium. Then, it involves replacing linear utility with power utility, recalculating the certainty equivalent and subtracting the first certainty equivalent to get the utility premium. The other two premiums are invariant to switching the order of calculation of the risk attitude premiums in this way. Presenting both orders allows us to see how sensitive the results are. As a general method, we would recommend taking the average, which is a commonly accepted way to assess the contribution of several factors to a non-linear model (as in the Shapley value, for instance).

Eq. 5 is a decomposition of the perceived welfare gain from actuarially fair insurance. The gain from insurance that is not actuarially fair can be decomposed by simply replacing the objective expectation of medical expenses conditional on observable determinants of medical need specific to the individual $(\mu)$ with some other price on the left hand side of the equation and in the definition of the belief premium. For example, by replacing $\mu$ with the unconditional expectation of medical expenses gives a decomposition of the perceived gain from insurance priced at the population average risk. This is what we do in our application. Similarly, the gain from subsidized insurance offered at a price below the average risk can be decomposed. In each case, this will change the belief premium only. This is the component of the decomposition that captures the divergence between the perceived fair price of insurance and its offer price, whatever the latter is (fair, pooled or subsidized).

\section{Health insurance in the Philippines}

Most Filipino households are covered by the National Health Insurance Program (NHIP), which is commonly known as Philhealth. This comprises an employment-based program that is mandatory for formal sector salaried employees, a fully subsidized program for the indigent targeted by a means test, a fully subsidized sponsored program for the near poor, people with disabilities, orphans and other 
disadvantaged groups ${ }^{14}$, a fully subsidized senior citizens program and a contributory overseas workers program. In addition, informal sector workers and the self-employed can voluntarily enroll at a premium of 2,400 pesos per year (\$50) if their average monthly income is 25,000 pesos $(\$ 540)$ or less. Above this income threshold, the premium is 3,600 pesos. However, since Philhealth cannot easily verify incomes of informal sector workers and the self-employed, most who enroll voluntarily pay the reduced premium. Coverage through all programs extends automatically to the spouse, children $(<21$ years old) and parents ( $>=65$ years) of the person qualifying. According to the Philhealth database, 89.4 million individuals in a population of around 100 million were covered in 2015 (Bredenkamp et al 2017). However, survey data consistently show a coverage rate that is lower by about 20 percentage points (Bredenkamp and Buisman 2016; Bredenkamp et al 2017). ${ }^{15}$ The gap in coverage is mainly because of low take-up of the voluntary program among those engaged in the informal economy.

The Philhealth benefit package includes a range of inpatient treatments at accredited public and private sector providers. Coverage of outpatient services and primary care is more limited. Despite the breadth of population coverage, there are gaps in the financial protection against medical expenses (Bredenkamp and Buisman 2016). This is due to the limited coverage of ambulatory care and medication, and also the latitude of providers to charge in excess of reimbursement ceilings set by Philhealth - balanced billing. Patients must pay out-of-pocket to cover the difference. In principle, providers are prevented from charging indigent and sponsored program members (i.e., the poor and disadvantaged) in excess of the reimbursement ceiling. However, this prohibition does not appear to be well enforced (Bredenkamp and Buisman 2016). In sum, in addition to the uninsured, those insured through Philhealth are likely to be exposed to considerable medical expenditure risk. For this group, we examine WTP for supplementary insurance to cover expenses not currently reimbursed.

\section{Data and method}

\subsection{Sample design}

Data were collected through a nationwide survey of 1780 Filipino households conducted in 2015 . This was a follow-up to a baseline survey carried out in 2011 as part of a randomized health insurance experiment (Capuno et al., 2016). The baseline had a multi-stage cluster sampling design to randomly select 2,950 households that were nationally representative (excluding the Autonomous Region of Muslim Mindanao). The follow-up targeted all households that, at baseline, were not covered by any Philhealth program, plus those that were covered either by the programs for the poor and disadvantaged

\footnotetext{
${ }^{14}$ Members of this program do not qualify via the means test administered by the Department of Social Welfare and Development but they enjoy fully subsidized cover due to their disadvantaged status with their contributions being paid for by local government, another government agency, a private entity or another individual.

15 The discrepancy partly arises because fully subsidized members, such as the poor and senior citizens, who are automatically enrolled are not aware of their insurance cover.
} 
or through voluntary enrollment. Interviews were conducted with 1513 households from these three groups. The attrition rate was about 24 percent (Bredenkamp et al 2017). ${ }^{16}$ In addition, a random sample of 267 households with mandatory, employment-based cover at baseline was selected for follow-up in order to increase the sample size for purposes unrelated to the analysis presented here. ${ }^{17}$

In the baseline survey, the enumerator was instructed to interview the head of the household or spouse if the head was unavailable. Only if it was impossible to interview either of them was another household member above 21 years old to be interviewed. In the follow-up, the intention was to interview the person who was the original household respondent in the baseline survey, or, if that person was unavailable, their spouse. ${ }^{18}$

We restrict the sample to respondents who answer all the questions needed to construct all components of the WTP decomposition (Eq. 5). We are left with 1565 observations out of the total of 1780 interviewed at follow-up. The 215 who are excluded are all dropped due to missing data on elicited risk attitudes. ${ }^{19}$

\subsection{Elicitation of beliefs about future medical expenditure}

Accumulating evidence supports the feasibility and value of eliciting subjective probabilities of various prospects in low-income and low-education settings (Attanasio, 2009; Delavande et al. 2011b; Delavande 2014). This is one of only a few studies to elicit subjective probabilities of future spending on medical care (Dercon et al 2015; Yilma et al 2018). We follow a common approach of using a visual aid to reduce the cognitive effort required to complete the task (Delavande et al. 2011b).

Respondents were asked to think of all expenditures on medical care and medicines that their household could incur in the next 12 months, excluding expenditures that would be reimbursed from health insurance if they had it. They were then presented with four cups labelled to represent ranges in which their household's total out-of-pocket (OOP) expenditure on healthcare over the next twelve

\footnotetext{
${ }^{16}$ Maintaining a nationally representative sample is not critical to the validity of our analysis. Nonetheless, online Appendix Table A1.1 presents balancing tests. There are some differences between households that were interviewed at follow-up and those that were not. In particular, households lost to follow-up were more likely to be urban, located in the capital region, richer, better educated and have fewer children. Generally, these are characteristics of more mobile households. We do not reweight the sample.

17 The larger sample size was required for analysis of smoking, not health insurance cover. In order to reach the target sample size, any household selected for this sample that could not be traced or interviewed was replaced with another random draw from the initially mandatorily insured households. There are only a few significant differences between the households from this group that were interviewed at follow-up and those that were not. Those not followed-up were less likely to be located in an urban setting and the capital region.

${ }^{18}$ In seeking consent, the enumerator informed that they were from an independent market research company and their purpose was not to sell anything. They explained that the survey was for a research project of the University of the Philippines School of Economics funded by the European Commission. The interviewee was assured that information provided would be treated with utmost confidentiality and used for research purposes only.

${ }^{19}$ See van Wilgenburg et al (2018) Appendix 7 for characteristics of these observations.
} 
months could fall: $0,1-4000$ pesos, $4001-8000$ pesos and $>8000$ pesos. They were given ten sticks and asked to distribute them by placing more sticks in a cup if they thought it more likely that their household's healthcare spending would lie in the range indicated by that cup. ${ }^{20}$ This procedure is similar to one that has been used to elicit the subjective probability distribution of a continuous variable in other low-income settings (Delevande et al. 2011a; Delevande et al. 2011b). It avoids making reference to the concept of probability that is unlikely to be understood by many of the respondents. It also avoids asking them to report a number. The exact protocol followed is set out in online Appendix 2.

The intervals of expenditure represented by the cups were selected on the basis of the crosssection distribution of expenditures in the baseline survey. Despite the right-skewed nature of the crosssection distribution, the middle two intervals were intentionally made of equal size to facilitate comprehension and to test for random distribution of the sticks. If beliefs are at least partly based on realized expenditures, then the sticks should not be distributed equally over the middle two intervals. We allow respondents to indicate a perception of a right-skewed distribution but do not impose this shape on the subjective distribution through the intervals offered. The last interval was left open to capture the perceived chance of extremely high expenditures.

After completing this task, the respondent was asked to make a comparative assessment of their household's medical expenditure risk by stating whether the chance that their household would spend more than 8000 pesos on healthcare in the next year was smaller, the same or larger than the risk for households similar to them.

\subsection{Estimation of subjective probability distributions}

We interpret a respondent's allocation of sticks to each of the four cups as corresponding to their perception of the likelihood that their household's medical expenditure over the next twelve months will fall in the respective interval. This gives us data points from which to estimate each respondent's subjective probability distribution of medical expenditures and so derive the perceived fair price for full insurance.

Let $c_{i}$ denote the number of sticks placed in cup $i$, where $i=0,1,2$ and 3 for the cups indicating 0,1 4000 pesos, $4001-8000$ pesos and $>8000$ pesos respectively. As explained in section 2 , we model each respondent's beliefs as a probability of not incurring any medical expenses, $p_{0}^{s}$, and a conditional

distribution, $f^{s}$, of non-zero expenditures. The value of $p_{0}^{s}$ is estimated by $\frac{c_{0}}{10}$. We allow for the possibility that the respondent is entirely certain of having no medical spending, i.e. $p_{0}^{s}=1$. If $p_{0}^{s} \neq 1$, we

\footnotetext{
${ }^{20}$ To elicit a subjective probability distribution of a continuous variable, survey respondents have typically been asked to distribute 10 or 20 items (Delavande 2011a). One experiment finds similar distributions irrespective of whether 10 or 20 beans are allocated (Delavande et al. 2011b).
} 
use nonlinear least squares to fit a truncated lognormal distribution (adapted to negative values ${ }^{21}$ ) on the conditional cumulative probabilities defined by

$$
F^{s}(-4000 \times i)=1-\frac{\sum_{j=1}^{i} c_{j}}{10-c_{0}}, \quad i=1,2,3 .
$$

We choose a truncated lognormal distribution since this allows for a long tail, which is typical for medical expenditures, without having to fix the maximum. We did not ask respondents to report their maximum possible expenditure. Even if we had, the reported amount could not be interpreted literally as the maximum (Delavande et al 2011a; Manski 2004). Note that Eq. 6 implies $F^{s}(-12000)=0$ for $i=3$. Using this point in the fitting prevents the distribution from being too fat at extremely high values. In (online) Appendix 3, we report checks on the sensitivity of estimates of the first two moments of the subjective distributions to fixing the point $F^{s}(x)=0$ at other values of $x$ and to using piecewise uniform and beta distributions rather than the truncated lognormal.

We substitute the individual-specific estimates of $p_{0}^{s}$ and $f^{s}$ for their objective counterparts in Eq. 1 to obtain the perceived fair price of full insurance, $\mu^{s}$.

\subsection{Estimation of fair price for average risk}

After reporting their expectations of future spending on healthcare, respondents were asked how much they spent OOP over the past 12 months. Specifically, they were asked in which of the same four intervals $(0,1-4000,4001-8000,>8000)$ was their household's total spending on healthcare net of any insurance reimbursements (see online Appendix 4). This allows us to directly compare the sample empirical distribution of past expenditures with the subjective probability distributions of future expenditures averaged over the sample. It also makes it possible to estimate a price for insurance equal to expenditure in the past year averaged over all households in a group that is fair for the average risk in that pool. We estimate prices specific to groups defined by whether insurance is held and, if so, what type (see Table 1). Each mean is obtained by fitting a truncated lognormal distribution to the cumulative frequencies of households within a group who report spending in the last year in each of the four intervals.

\subsection{Specification and elicitation of risk attitudes}

Given data were collected in the field from a sample including many individuals with low educational attainment, to make the elicitation task feasible and comprehensible we purposely limited the number of preference parameters. We use one-parameter forms for the PT value function and the probability weighting function that tend to perform best compared with (combinations of) popular alternatives

\footnotetext{
${ }^{21}$ Let $G$ be the cumulative distribution of the lognormal. We used $F^{s}(x)=1-G(-x)$.
} 
(Stott 2006). For the value function, we use power utility, $u(x)=-\lambda(-x)^{\gamma}$, where $\lambda$ represents loss aversion and $\gamma$ captures utility curvature in the domain of losses ( $\gamma \leq 1$ for convexity). Since the decision involves contemplating prospects in the loss domain only, the loss aversion parameter drops out of expressions for WTP. Substituting this specification into Eq. 3, we get:

$$
W_{u}=\left[\frac{\left(1-p_{0}^{s}\right) \int_{-\max }^{0}-\lambda(-x)^{\gamma} f^{s}(x) d x}{-\lambda}\right]^{1 / \gamma}=\left[\left(1-p_{0}^{s}\right) \int_{-\max }^{0}(-x)^{\gamma} f^{s}(x) d x\right]^{1 / \gamma} .
$$

This is calculated for each respondent given the estimates of $p_{0}^{s}$ and $f^{s}$ that define their subjective probability distribution and the estimate of $\gamma$ we elicit from them (see below). In all computations, we set $\max =500,000$, truncating the lognormal at that value. This was large enough to have negligible impact on the results.

We used the one-parameter weighting function $w(p)=\exp \left(-(-\ln (p))^{\alpha}\right)$ introduced and axiomatized by Prelec (1998). The parameter $\alpha$ captures likelihood insensitivity: $\alpha<1$ gives an inverse S-shaped function - overweighting small probabilities and underweighting moderate/large probabilities; $\alpha>1$ gives an S-shape - underweighting small probabilities and overweighting moderate/large probabilities; and, $\alpha=1$ gives a linear function as in EU (Tversky and Kahneman, 1992). From this function, we obtain $w^{\prime}(p)=\frac{\alpha}{p}(-\ln (p))^{\alpha-1} \exp \left(-(-\ln (p))^{\alpha}\right)$. We substitute this and the power utility function into Eq. 4 and invert to get an expression for $W T P_{P T}$, which we evaluate for each respondent using estimates of their subjective probability distribution, $\gamma$ and $\alpha$.

To elicit the risk attitude parameters, we designed a method suitable to meet the challenge of separately identifying utility curvature and probability weighting in the time-constrained context of a field survey of individuals who can have low educational attainment. Details are given in Van Wilgenburg et al (2018) and online Appendix 5. Respondents were offered two independent sets of hypothetical lottery choices in the loss domain. Each lottery was presented using a visual device. One set of lotteries identified the sure loss that the respondent found equivalent to facing a $50 \%$ chance of another loss. This first indifference could be used to identify utility curvature $(\gamma)$ assuming EU. The second set identified the loss faced with a $50 \%$ probability that the respondent was prepared to accept rather than take a lottery over two losses with unequal probabilities. The losses and probabilities were fixed such that an EU maximizer would have the same point of indifference in both sets of lotteries. Hence, the difference between the selected points of indifference identifies probability weighting. Each pair of indifferences uniquely identifies the values of parameters $\gamma$ and $\alpha$ (see Van Wilgenburg et al, 2018). 


\subsection{Elicitation of willingness to pay}

WTP for health insurance was elicited using two methods that were randomized between respondents. One is an iterative bidding approach. It starts by asking the respondent whether they would pay 500 pesos per month for health insurance that would cover all medical expenses (including related transportation costs) for their entire household. Depending on whether the hypothetical offer is accepted or rejected, it is subsequently raised or lowered and the bidding continues until the respondent changes their response to the offer. If the respondent claims to be willing to pay more than 900 pesos, they are asked to state the amount they would pay.

The other method lists a number of intervals each with a range of 100 pesos and asks the respondent to pick the one within which their WTP is located. The intervals list amounts up to 900 pesos, with a final option to indicate the WTP amount if it exceeds that value. The protocol for the WTP questions is set out in online Appendix 6. The interviewee was informed that the survey was commissioned by a university (not a commercial or government agency selling insurance) for the purpose of academic research only. They had no incentive to distort their reported WTP in order to influence the price of insurance.

The respondent is asked how much they would be willing to pay for insurance that would cover all the medical expenses their household will incur. The question is not explicit about whether it is referring to expenses gross or net of those that would be reimbursed through any insurance the household currently has. If an insured respondent interprets the question as asking about gross expenses, then there is an inconsistency between this directly elicited WTP and both the estimated fair price and the perceived fair price of insurance, each of which is derived from a distribution (empirical and subjective) of OOP expenditures net of insurance reimbursement. It is impossible to know how each respondent interprets the WTP question. Since they are asked to state WTP for insurance covering expenses they will incur, it may be reasonable to assume that they will factor out expenses that would be covered by their current insurance. In that case, there is no problem. We measure stated WTP for supplementary insurance. Otherwise, for insured households, the reported WTP will be inflated relative to the estimated fair price and this upward bias will be captured by a larger (in value, not magnitude) residual $\left(\pi^{\varepsilon}\right)$ in the decomposition given by Eq. 5 . In fact, we find that the average residual is negative for the insured, which suggests that there is little or no such bias. Even if it is present, it will not affect the other three components of the decomposition. And it is not present for uninsured households, which is our focus and the group of interest with respect to explaining low demand for insurance.

\subsection{Sample characteristics}

The vast majority of respondents are either the household head (545/1565) or their spouse (839/1565). Table 1 reports means of other characteristics. The majority of respondents are female. Their average 
age is about 45 years. They are approximately evenly divided between urban and rural locations. About one tenth have at least some college education.

A majority of respondents reported that their household spent 1-4000 pesos on healthcare in the past year. A little more than a fifth reported spending nothing and 11 percent spent more than 8000 pesos. Consistent with a bias towards optimism (Weinstein 1980; Weinstein and Klein 1996), the fraction (34\%) perceiving that their risk of incurring medical expenses in excess of 8000 pesos is smaller than that for similar households is almost double the fraction $(18 \%)$ that perceives their risk to be greater.

Respondents were asked whether each member of the household was covered by health insurance. We use the insurance status of the respondent to categorize households as insured or uninsured. Since Philhealth cover is extended to the spouse, children and parents of a member, there is little intra-household variation in insurance. On average, around $90 \%$ of other individuals in the household have the same coverage status as the respondent. Two thirds of respondents are insured. Around 46 percent are covered either by the mandatory program for formal sector employees or one of the two fully subsidized programs for the poor and disadvantaged groups. Only 9 percent enroll voluntarily.

Consistent with PT, on average, respondents are risk seeking for losses as characterized by utility curvature $(\gamma<1)$. In fact, around 80 percent of the sample has convex utility over losses (Figure $2 \mathrm{a}$ ). The mean of the probability weighting parameter (Prelec alpha) is close to 1 indicating that, on average, there is no deviation from EU. Just under half of the sample make lottery choices consistent with EU $(\alpha=1)$. However, there is substantial variation in the nature and degree of probability weighting (Figure $2 \mathrm{~b}$ ). Around a third overweight small probabilities $(\alpha<1)$, while a fifth underweight them $(\alpha>1)$. See Van Wilgenburg et al (2018) for further analysis of the elicited risk attitudes and their association with insurance status.

The average WTP for health insurance coverage is 171 pesos per month, which is about 30 pesos less than the premium for low-income households joining Philhealth voluntarily. This is also far below both the 500 pesos starting point in the iterative bidding elicitation of WTP and the midpoint (450 pesos) with the showcard approach. This suggests there was little anchoring on the starting value in the first case and no strong tendency to gravitate to the middle value in the second. 


\begin{tabular}{|c|c|c|}
\hline & Mean & Std. Dev. \\
\hline \multicolumn{3}{|l|}{ Demographics } \\
\hline Male (respondent) & 0.276 & \\
\hline Age (respondent - years) & 46.8 & 13.0 \\
\hline Urban & 0.454 & \\
\hline Number of household members & 5.14 & 2.27 \\
\hline Number of household members aged $<15$ or $>=65$ & 1.82 & 1.51 \\
\hline \multicolumn{3}{|l|}{ Socioeconomic status } \\
\hline \multicolumn{3}{|l|}{ Highest education completed (respondent) } \\
\hline None & 0.201 & \\
\hline Elementary school & 0.255 & \\
\hline High school & 0.440 & \\
\hline College or more & 0.104 & \\
\hline Log of per capita household income (continuous) & 10.230 & 1.06 \\
\hline \multicolumn{3}{|l|}{ Health care, expenditure and insurance } \\
\hline At least one hospital inpatient stay in past year (household) & 0.100 & \\
\hline \multicolumn{3}{|l|}{ OOP medical expenditure in the past year (household) } \\
\hline None & 0.211 & \\
\hline $1-4000$ pesos & 0.534 & \\
\hline $4001-8000$ pesos & 0.141 & \\
\hline$>8000$ pesos & 0.114 & \\
\hline \multicolumn{3}{|l|}{ Health insurance (respondent) } \\
\hline None & 0.348 & \\
\hline Mandatory (formal economy salaried employees + dependents) & 0.194 & \\
\hline Sponsored (fully subsidized for near poor, disabled, orphans, etc.) & 0.113 & \\
\hline Indigent (fully subsidized for poor - means-tested) & 0.147 & \\
\hline Voluntary (informal economy workers + dependents) & 0.086 & \\
\hline Other insurance & 0.079 & \\
\hline Don't know if insured & 0.033 & \\
\hline \multicolumn{3}{|l|}{ Perceived risk of medical spending $>8000$ pesos (respondent), } \\
\hline Smaller than similar households & 0.339 & \\
\hline Same as similar households & 0.484 & \\
\hline Larger than similar households & 0.177 & \\
\hline \multicolumn{3}{|l|}{ Elicited risk attitudes and WTP } \\
\hline Utility curvature, $\gamma$ (continuous) & 0.487 & 0.491 \\
\hline Probability weighting (Prelec's alpha), $\alpha$ (continuous) & 1.029 & 0.739 \\
\hline$\alpha<1$ & 0.323 & \\
\hline$\alpha=1$ & 0.482 & \\
\hline$\alpha>1$ & 0.196 & \\
\hline WTP for insurance (pesos per month) & 171 & 149 \\
\hline$N$ & 1565 & \\
\hline
\end{tabular}

Notes: Unless otherwise stated, each variable takes the value of 1 if the characteristic is present and is 0 otherwise. For education there are 1558 observations. For income there are 1462 observations. For other variables, sample sizes are as in bottom row. 'Other insurance' includes those with more than one type of insurance. 
a) Utility curvature $(\gamma)$

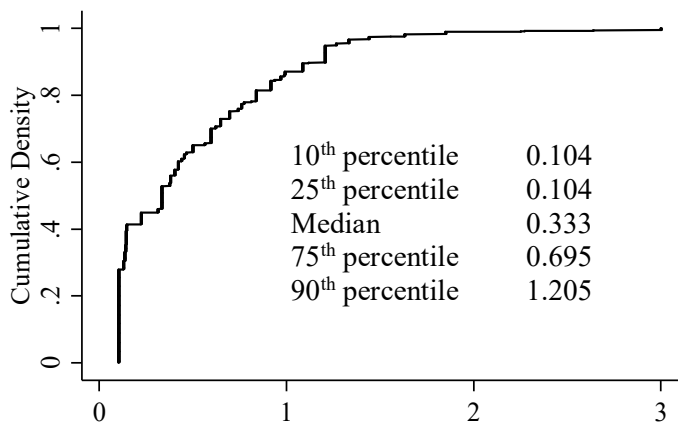

b) Prelec alpha $(\alpha)$

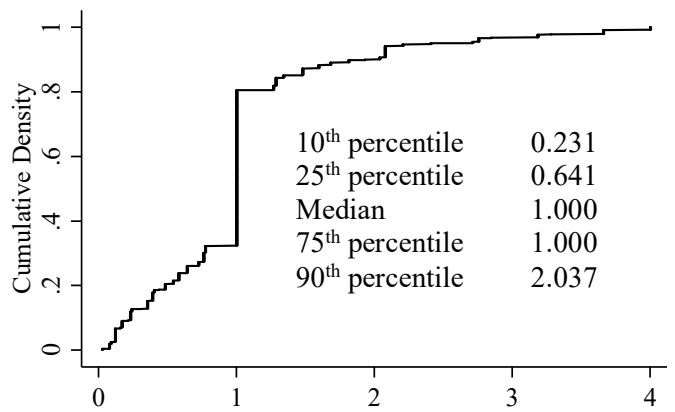

Figure 2: Empirical distributions of elicited risk preference parameters

\section{Elicited beliefs and subjective distributions of medical expenses}

Before presenting the behavioral decomposition of WTP for insurance, we first examine the elicited beliefs about future medical expenses that are critical to it. We start by presenting the raw data on the elicited beliefs and then show estimates of moments of the subjective probability distributions of medical expenses derived from them. We then assess whether and how these moments correlate with past medical spending and other covariates in order to establish the information respondents appear to use in forming their reported beliefs. Since the purpose of this section is to assess the validity of the subjective probability data, we lump insured and uninsured respondents together.

\subsection{Raw belief data}

All respondents answered the questions designed to elicit their subjective distributions of spending on medical care. On average, respondents put most sticks in the cup indicating spending of 1-4000 pesos, perceiving a 44 percent chance of incurring medical expenses in that range (Figure 3). This is 10 percentage points less that the fraction of households that did spend in that interval in the previous year (Table 1). Nonetheless, the fact that the respondents, on average, attribute the greatest likelihood to spending in the range that has that greatest density in the empirical distribution of actual spending indicates a degree of correspondence between the subjective and objective distributions.

Spending between 4001 and 8000 pesos has the next highest average perceived likelihood, which at 0.2 is above the proportion of households (0.14) that did spend in this range in the last year. The perceived risk of spending in excess of 8000 pesos is also overestimated ( 0.17 vs 0.11$)$, on average. There is only slight underestimation of the probability of incurring no expenses ( $0.19 \mathrm{vs} 0.21)$. The fact that sticks were not divided evenly over the four cups provides further indication that respondents did not allocate them randomly. The data may well contain information on beliefs about future medical spending. 

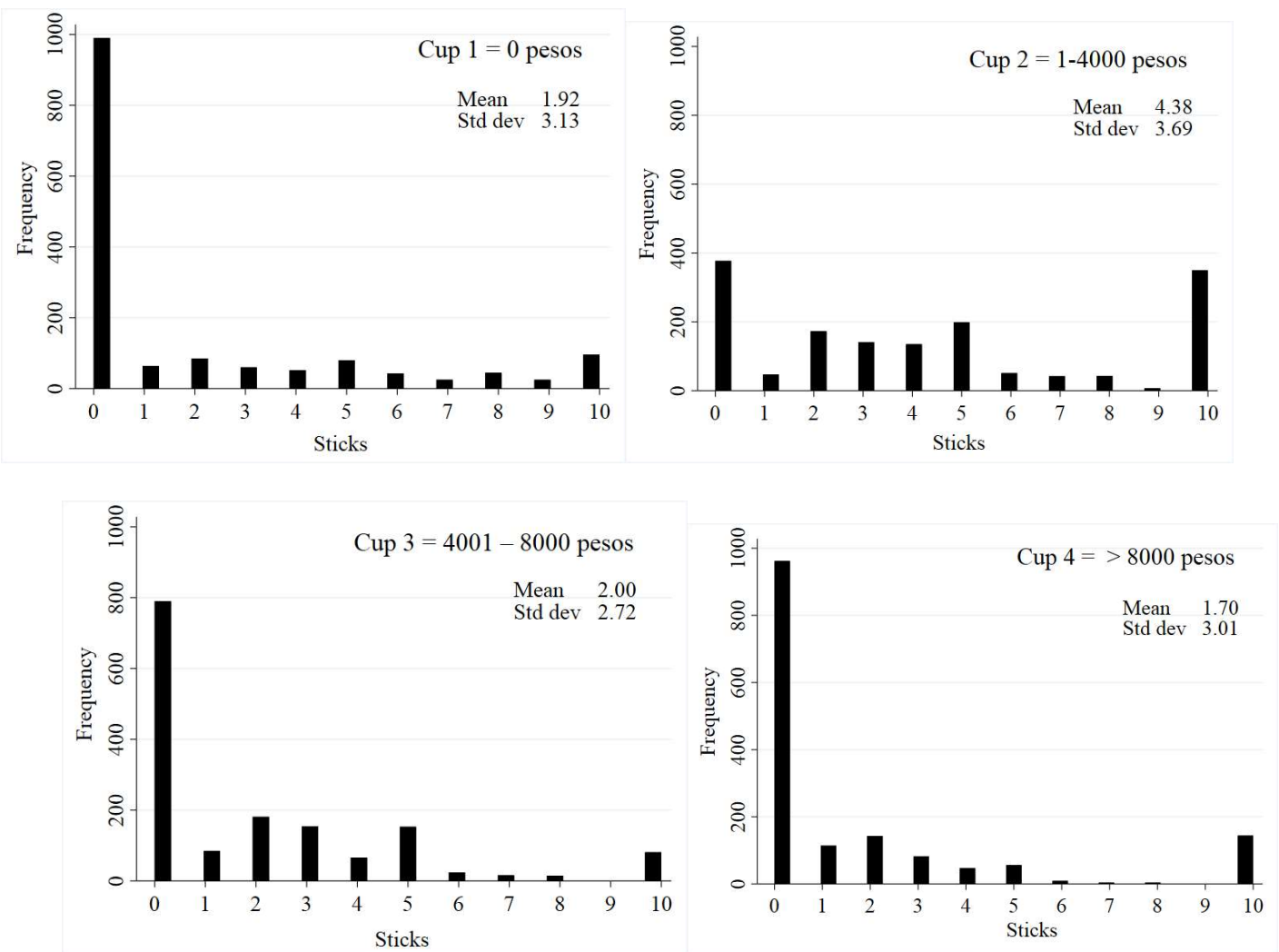

Figure 3. Distribution of sticks across cups representing ranges of medical expenditure

In total, 671 out of 1565 respondents put all 10 sticks in one cup. According to the instructions they were given, this expresses certainty that their spending would fall in that range. It may result from the relatively broad intervals of spending used. About half (350) of the respondents who expressed certainty put all sticks in the cup indicating spending between 1 and 4000 pesos. It could also reflect overconfidence in the predictions, which is a common feature of elicited beliefs (Lichtenstein et al. 1982).

Many respondents do not place any sticks at all in at least one of the cups, ruling out the possibility of incurring that level of spending. This tendency is most common at the two extremes. Nearly two thirds (64\%) of the respondents believe there is no chance that they will avoid incurring medical expenses altogether, and around three fifths rule out spending more than 8000 pesos. More than a third $(37 \%)$ do not place any sticks in either of the cups representing the two extremes. These respondents appear to perceive limited exposure to medical expenditure risk defined as volatile expenses. 


\subsection{Estimates of subjective distributions}

Table 2 shows sample statistics of the estimates of the first moment $\left(\mu^{s}\right)$ and square root of the second moment $\left(\sigma^{s}\right)$ of the subjective distribution of medical expenditures for each household. ${ }^{22}$

Table 2. First two moments of subjective distribution of medical expenditure-sample statistics

\begin{tabular}{|c|c|c|c|c|c|c|c|}
\hline \multirow[t]{2}{*}{ 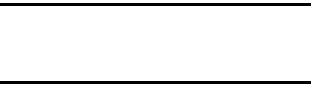 } & \multirow[t]{2}{*}{ Mean } & \multirow[t]{2}{*}{ Std. Dev. } & \multicolumn{5}{|c|}{ Percentiles } \\
\hline & & & p25 & p50 & p75 & p90 & $\mathrm{N}$ \\
\hline First mon & 3 & 3,291 & 78 & 3,217 & 5,670 & 8,1 & 1,5 \\
\hline Second moment $\left(\sigma^{s}\right)$ & 1,323 & 1,868 & 51 & 274 & 2,891 & 4,409 & 1,565 \\
\hline
\end{tabular}

Notes: Columns give summary statistics of the sample distribution of household-specific estimates of the first two moments of the subjective distribution of medical expenditures. The square root of the second moment $\left(\sigma^{s}=\left(\left(1-p_{0}\right) \int_{-\max }^{0} x^{2} f^{s}(x) d x-\left(\mu^{s}\right)^{2}\right)^{1 / 2}\right)$ is given.

The sample mean of the estimates of the first moment of the household-specific subjective distribution of OOP expenditures, i.e. the mean of subjectively expected expenditure that is equivalent to the perceived fair price of full insurance, is 3,341 pesos. This is reasonably close to the sample mean of actual spending in the previous year, 3,146 pesos. The mean of actual spending is lower because, on average, respondents overestimate the likelihood of incurring expenses in the top two categories. ${ }^{23}$

The sample mean of the square root of the second moment of the subjective probability distribution is less than half the sample mean of the first moment. ${ }^{24}$ This contrasts with the common finding - evident also in our data - that the standard deviation in OOP spending across households is substantially larger than the cross-section mean (e.g. Van Doorslaer et al, 2007). This means that attempts to approximate (perceived) risk exposure from measures based on the cross-sectional variance of medical spending lead to substantial overestimation. Household-specific risk is confounded by predictable heterogeneity in spending across households. Separation of the two is an important advantage of collecting data on households' perceived prospects of future spending.

\footnotetext{
22 See online Appendix 3, Table A3.1 for the sensitivity of the estimates to assuming beta and the piecewise uniform distributions instead of truncated lognormal, and to using upper bounds of 20,000 pesos and 50,000 pesos, instead of 12,000 pesos, for the top interval of medical expenses to which respondents were asked to assign probabilities.

${ }^{23}$ Using data from Ethiopia, Yilma et al (2018) find, as we do, that respondents overestimate their expected spending on medical care only to a modest extent. In contrast, Dercon et al (2015) in a study conducted in Kenya that confines attention to spending on hospital inpatient care find that the sample mean of the subjective expectations exceeds the mean of actual expenditure by $1518 \%$.

${ }^{24}$ Yilma et al. (2018) also find that the standard deviation of the subjective distribution tends to be less than its expected value.
} 


\subsection{Correlates of moments of subjective distributions}

The rows of Table 3 split the sample into four categories according to spending in the previous year. The cells show the subjective probability that spending in the next year will fall in each of the same four categories averaged over the subsample defined by past expenditure. For example, the top left cell indicates that, on average, those with no OOP medical spending in the previous year believe they have a 43 percent chance of not incurring any expenses again in the coming year. As the level of spending in the previous year rises, the subjective probability of incurring no medical expenditure in the next year falls significantly, if not quite monotonically. This is consistent with the respondents believing that spending on healthcare is positively serially correlated, and so using their past experience to forecast future expenses. Moving across columns confirms the significant positive association between forecast and past spending. The mean probability is nearly always largest on the diagonal: the subjective probability of future spending falling in an interval is highest among those who incurred expenses in that interval in the previous year.

Table 3: Mean subjective probabilities of future medical expenditure by past expenditure

\begin{tabular}{lccccc}
\hline & \multicolumn{6}{c}{ Medical expenditure next year (pesos) } & $\mathrm{N}$ \\
Medical expenditure previous year & 0 & $1-4000$ & $4001-8000$ & $>8000$ & \\
\hline 0 & 0.43 & 0.35 & 0.12 & 0.10 & 330 \\
$1-4000$ & 0.15 & 0.55 & 0.19 & 0.11 & 836 \\
$4001-8000$ & 0.07 & 0.39 & 0.36 & 0.18 & 221 \\
$>8000$ & 0.08 & 0.16 & 0.18 & 0.59 & 178 \\
Equal means: p-value & 0.000 & 0.000 & 0.000 & 0.000 & \\
\hline
\end{tabular}

Notes: Each cell shows the mean proportion of sticks placed in the cup corresponding to the interval of future medical expenditure defined by the column heading across households with past expenditure in the interval defined by the row heading. The bottom row gives the p-value of a F-test of equal means across the four categories of past expenditure.

The correlation coefficient between expected spending (first moment of the subjective distribution) and past spending calculated as the mid-point of the reported interval is 0.49 . The regressions presented in Table 4 show that this association between subjective expectations and past experience continues to be strong and significant after controlling for demographics, socioeconomic characteristics and insurance status. Expected spending rises monotonically and significantly in moving from those who report having spent nothing on medical care in the previous year to those who claim to have spent more than 8,000 pesos. On average, those in the latter category expect to spend almost 5,000 pesos more over the next year than those in the former. There is a perceived high degree of positive serial correlation in medical expenditures. 
Medical expenditure in the past year $($ ref. $=0)$

$1-4000$ pesos

4001-8000 pesos

$>8000$ pesos

At least one hospital inpatient stay in past year

Log of per capita household income

Urban

Number of household members

Proportion of household members $<15$

Proportion of household members $>65$

Highest education completed (ref. no schooling) Elementary school

High school

College or more

Health insurance (ref. uninsured)

Mandatory (formal economy employees + dependents)

Sponsored (fully subsidized for disadvantaged)

Indigent (fully subsidized for poor)

Voluntary (informal economy workers + dependents)

Other insurance

Don't know if insured

Constant

Observations

R-squared

Notes: Robust standard errors in parentheses ${ }^{* * *} \mathrm{p}<0.01,{ }^{* *} \mathrm{p}<0.05,{ }^{*} \mathrm{p}<0.1$. Sample size is less than 1565 due to missing values on income.

$\begin{array}{cc}558 * * * & 391 * * * \\ (198) & (111) \\ 2,462 * * * & 1,004 * * \\ (256) & (170) \\ 4,817 * * * & 281 * \\ (328) & (166) \\ 236 & -177 \\ (304) & (193) \\ 58 & 4 \\ (74) & (49) \\ -353 * * & -384 * * * \\ (158) & (102) \\ 58 & -3 \\ (39) & (23) \\ 299 & 302 \\ (385) & (231) \\ 411 & -122 \\ (594) & (347) \\ & \\ 370 * & 71 \\ (223) & (151) \\ 208 & -212 \\ (211) & (141) \\ 890 * * * & 157 \\ (308) & (206) \\ & \\ 118 & -10 \\ (215) & (140) \\ 781 * * * & -90 \\ (249) & (169) \\ 427 * & -293 * * \\ (255) & (141) \\ 981 * * * & 308 \\ (305) & (203) \\ -72 & 206 \\ (304) & (198) \\ -498 & 165 \\ (437) & \\ 716 & \\ (862) & \\ 1,456 & \text { due to missing } \\ 0.24 & \\ \text { Sample size is less } & \\ & \\ & \\ & \\ & \end{array}$


Rather surprisingly, expected spending on medical care does not seem to vary with income. ${ }^{25}$ But it does rise strongly with education. College graduates expect to spend around 900 pesos more than those without any education. Urban dwellers expect to spend around 350 pesos less than those living in rural areas. This may be because transport costs are included. Expected expenditure also varies with insurance cover. It is highest among those who enroll voluntarily. This may indicate adverse selection, although it needs to be borne in mind that respondents are instructed to give probabilities of incurring medical expenses excluding spending that will be reimbursed by insurance. Overall, the covariates explain almost a quarter of the sample variation in the subjective expectations. This is a good deal of systematic variation, indicating that the elicited subjective probabilities contain much more than noise.

The second moment of the subjective distribution is also found to be significantly associated with medical spending in the previous year. Compared with households who spent nothing in the previous year, those who spent in any of the other intervals report subjective probabilities that imply a more dispersed distribution and greater medical expenditure risk. Those who spent 4001-8000 pesos in the previous year perceive the highest volatility. Urban dwellers perceive less variation than those living in rural areas.

Table 5. Expected medical expenditure $\left(\mu^{s}\right)$ by comparative assessment of risk

\begin{tabular}{lccc}
\hline \hline Risk that OOP $>8000$ pesos compared with others & \multicolumn{3}{l}{ Subjective expectation of OOP } \\
& $\left(\mu^{s}\right)$ & \\
\hline & Mean & Median & $\mathrm{N}$ \\
Smaller & 2014 & 78 & 531 \\
Same & 3446 & 3769 & 757 \\
Larger & 5601 & 6085 & 277 \\
Equality across groups - p-value & 0.000 & 0.000 & \\
Notes: Mean and median of subjective expectations across subsamples defined by categories of comparative measure of \\
future medical spending.
\end{tabular}

If a respondent holds and is able to report beliefs about their future spending on healthcare, then there should be consistency across their answers to different types of questions about that spending. Each respondent was asked whether the chance that they would spend more than 8000 pesos on medical care in the next year was smaller, the same or greater than that for similar households. Provided 'similar' is not interpreted to mean households with the same needs for healthcare and an equal economic capacity to meet those needs, then, if the respondents' beliefs are well-formed and they are able to express them through answers to both the subjective probability and comparative questions, we should observe those reporting a smaller relative chance of spending above 8,000 pesos tend also to give subjective probabilities that imply a lower expected level of expenditure. This is precisely what we see in Table 5. Both the sample mean and median of expected spending rise monotonically, substantially

\footnotetext{
25 This may be due to measurement error in the income variable. The variable includes income from different sources including salary, entrepreneurial activities, remittances and other sources.
} 
and significantly on moving from those reporting a smaller chance of spending more than 8000 pesos to those reporting a greater chance. This is consistent with respondents holding reasonably consistent beliefs about future medical spending and our method of eliciting those beliefs in the form of subjective probabilities being at least partially successful.

\section{Willingness to pay for insurance and its decomposition}

We first examine and decompose the WTP of the uninsured for insurance. We then consider WTP of the already insured for supplementary insurance.

\subsection{WTP of the uninsured}

The left-hand column of Table 6 summarizes the distribution of the PT model-derived WTP (Eq. 4) calculated from the subjective distributions of medical expenditures and elicited risk attitude parameters. The mean is approximately equal to the 2,400 pesos premium at which those with lower incomes could have enrolled in the social health insurance program (Philhealth). ${ }^{26}$ However, the median is only 192 pesos (\$4), and so for a majority the model correctly predicts that insurance is not demanded at this premium. Consistent with revealed preferences, the model indicates that the 61.5 percent of respondents with $W T P_{P T}$ less than 2,400 pesos perceive themselves to be made worse off if they were to insure at this premium (Figure 4a). In fact, the model predicts that around two fifths of the uninsured would not demand insurance at any (positive) price. However, for a little less than two fifths $(38.5 \%)$ it is predicted that they would be better off in welfare terms if they were to enroll at the reduced premium $\left(W T P_{P T}>2,400\right)$ and one third would even enjoy a consumer surplus from purchasing insurance at the non-reduced price of 3,600 pesos, which is more than 500 pesos above the actuarially fair premium for the average risk in this pool. PT risk attitudes and risk perceptions do not fully explain the decision of these individuals not to insure.

The second column from the left of Table 6 summarizes the distribution of directly elicited WTP. ${ }^{27}$ The mean is lower than the mean WTP derived from the model parameterized using the elicited risk perceptions and attitudes. It is also around 350 pesos (\$7.20) below the reduced premium of 2,400 pesos. The median stated WTP is only half of this premium. The vast majority of the uninsured state a WTP that is consistent with their decision not to insure: $W_{T} P_{R}<2,400$ for 84 percent and $W T P_{R}<3,600$ for 89 percent (Figure 4a). Stated preferences are more consistent with revealed preferences than are

\footnotetext{
${ }^{26}$ Our income data are not sufficiently detailed to check whether each respondent's income lies below the threshold at which they are entitled to the reduced premium. In any case, as mentioned in section 3, most can enroll at this premium because it is difficult for Philhealth to verify incomes.

27 The amount each respondent reported being willing to pay per month for insurance has been converted to the annual equivalent to make the magnitudes comparable with those obtained using our indirectly derived measure. The average WTP using the iterative bidding method is 2208 pesos, while the average from the list method is 1884 pesos $(\mathrm{p}=0.0453)$.
} 
model-derived preferences. This suggests that stated WTP is influenced by factors other than risk perception and PT risk attitude that drive down the demand for insurance. These influences are picked up by the residual term of the decomposition. Even the 11-16 percent of respondents who state a valuation of insurance greater than the price at which they could purchase it are not necessarily inconsistent. They were asked to report WTP for insurance that would cover all medical expenses. Philhealth neither promises nor delivers this. The revealed WTP for this product should be less than the stated WTP for full insurance. The amounts reported for the latter, however, suggest that more than four fifths of the uninsured would not be interested in insurance that fully covered all of their medical expenses and was fairly priced for the average risk in this group (Figure $4 b$ ).

Table 6: Willingness to pay for insurance and its decomposition-uninsured households

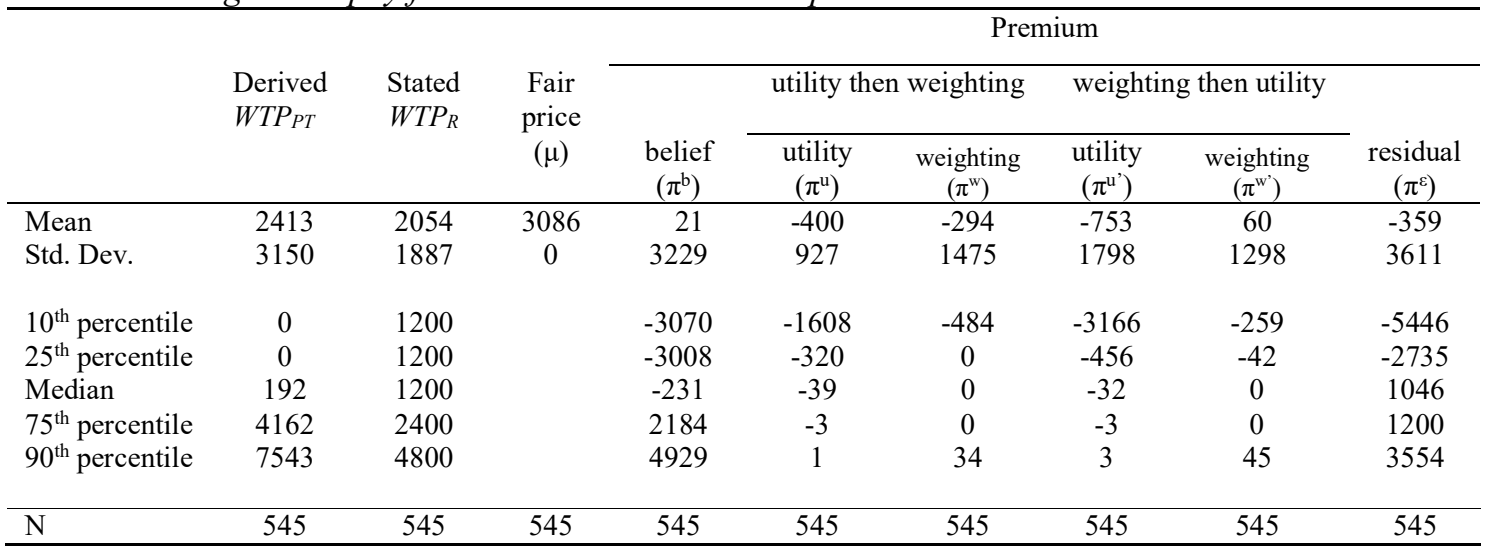

Notes: Table only includes respondents who report being uninsured. Derived WTPPT is obtained from Eq. 4 using the subjective distribution of medical expenses and elicited risk attitudes. Fair price is the estimated mean expenditure obtained from the empirical distribution of reported past expenditures among the uninsured. Columns under heading 'Premium' give the components of the decomposition (Eq. 5). In columns headed "utility then weighting", utility premium is calculated first by applying power utility with linear probability weighting. Then the weighting premium is calculated by introducing the probability weighting function to weight power utility. In the columns headed "weighting then utility" the weighting premium is calculated first by applying the probability weighting function to linear utility. Then the utility premium is calculated by changing linear to power utility.

a) Stated $W T P_{R} \&$ model-derived $W T P_{P T}$

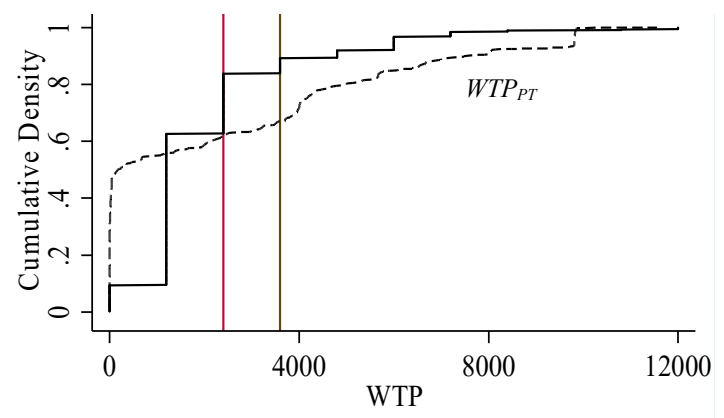

b) Consumer surplus from fair full insurance

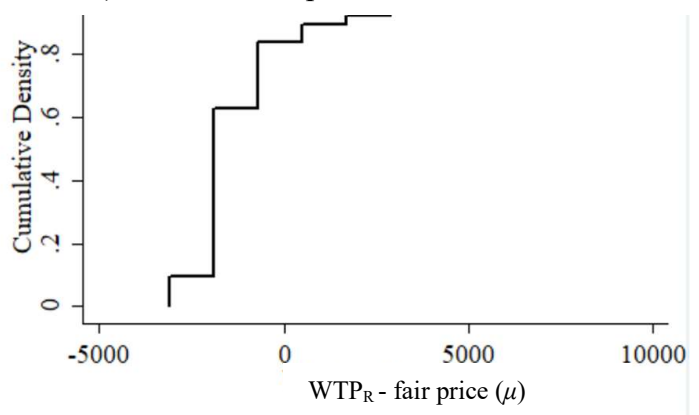

Figure 4: Distributions of willingness to pay and consumer surplus - uninsured

Notes: Panel a) shows the CDFs of $W T P_{R}$ and $W T P_{P T}$ for uninsured respondents. Left (right) vertical line indicates subsidized (full) premium. Right vertical line indicPanel b) shows CDF of $W T P_{R}$ minus the fair price of full insurance for the average risk among the uninsured defined as in the notes to Table 6. Sample size is 545 . 


\subsection{Decomposition of WTP of the uninsured}

The remaining columns of Table 6 present the fair price of full insurance for the average risk, which is simply the mean medical expenditure incurred by the uninsured, and our decomposition of the difference between the stated WTP and this fair price (Eq. 5). The mean stated WTP is more than 1000 pesos less than the fair price. This is not because of downwardly biased expectations. On average, uninsured respondents have a belief premium close to zero. Their expectations are approximately unbiased..$^{28}$ The mean perceived fair price of 3,107 pesos $(=3,086+21)$ is substantially above the 2,400 pesos reduced premium at which Philhealth offers cover. Hence, according to these estimates, a lowincome uninsured household with mean beliefs would have decided to insure if it were risk neutral or a risk averse EU maximizer. The decision not to insure may be because Philhealth does not provide full insurance. It could also be that insurance decisions are not explained well by the EU model with risk aversion. The mean perceived fair price is less than the 3,600 pesos premium at which insurance is available to those with (declared) higher incomes. Such households with mean beliefs would need to have a risk premium of at least 493 pesos $(=3600-3107)$ in order to be persuaded to join Philhealth even if it were to deliver full insurance. Their revealed preference indicates that they are not so risk averse, or something else diminishes their demand for insurance. ${ }^{29}$

There is a great deal of variation in beliefs. The standard deviation of the belief premium dwarfs the mean. This premium is negative for a majority (about 55\%) of the uninsured (Figure 5a). That is, most expect to spend less on healthcare than the average expenditure incurred by the uninsured in the past year. This is consistent with most of the uninsured being optimistically biased and this contributing to the decision not to insure. But this is not the only interpretation. It may not even be the most plausible one. Healthier respondents may correctly perceive that the right-skewed cross-sectional distribution of medical expenditures does not represent the risk to which they are exposed. The high expenses incurred by the minority of unhealthy respondents can raise the sample mean above the unbiased subjective expectations of the majority of healthier respondents. If we were to define fair prices conditional on household-specific characteristics, including chronic health conditions, rather than being fair for the group-average risk, then the variance in the belief premiums would fall. This would come closer to a decomposition of WTP for insurance that is actuarially fair for each household. But it would not help us understand demand for the fixed-price social insurance offered in the Philippines.

\footnotetext{
${ }^{28}$ Strictly, this is true only if there is no change in the mean of actual spending from one year to the next.

${ }^{29}$ As mentioned earlier, because of the difficulty of verifying the income of informal sector workers, few enroll in Philhealth's voluntary program at the higher premium. Hence, the fact that the mean perceived fair price is below this premium is not so relevant in explaining the decision to remain uninsured.
} 
a) Belief premium $\left(\pi^{b}=\mu^{s}-\mu\right)$

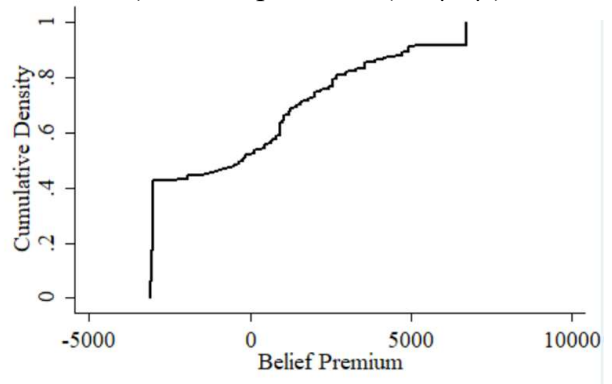

c) Weighting premium $\left(\pi^{w}=W T P_{P T}-W T P_{u}\right)$

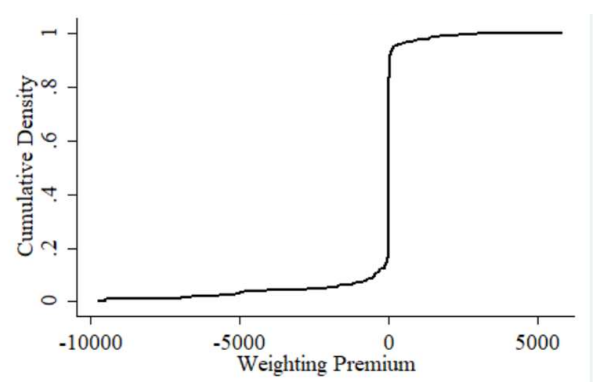

b) Utility premium $\left(\pi^{u}=W T P_{u}-\mu^{s}\right)$

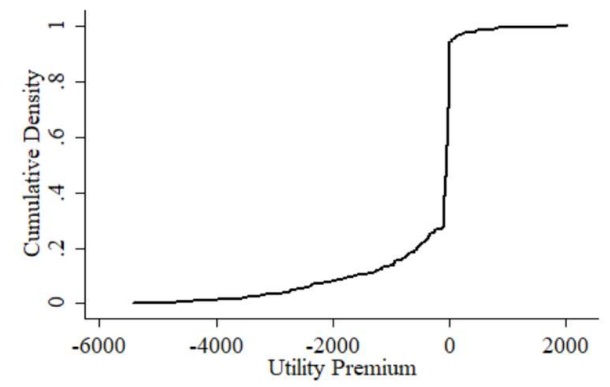

d) Residual $\left(\pi^{\varepsilon}=W T P_{R}-W T P_{P T}\right)$

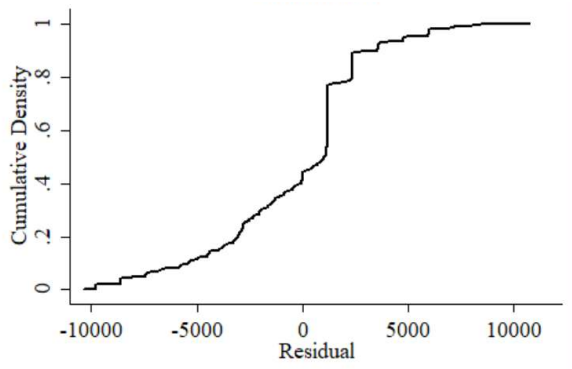

Figure 5: Distributions of components of decomposition of WTP less fair price-uninsured households

Notes: CDFs of the four terms on the right hand side of Eq. 5. Utility and weighting premiums obtained in that order. Uninsured households. Sample size is 545.

Using the decomposition that first identifies the contribution of utility curvature and then that of probability weighting ("utility then weighting" in Table 6), the means of both risk attitude premiums are negative indicating risk seeking, on average. This explains a large part of the shortfall of the mean stated WTP from the fair price for the average risk. Given the sum of these two (mean) preferencerelated premiums is negative, WTP obtained from applying the PT model to the subjective distributions of medical expenses is less than the perceived fair price of insurance. ${ }^{30}$ According to this model, the average uninsured respondent would not purchase insurance that fully covered their medical expenses and they perceived as being offered at an actuarially fair price. They would anticipate a welfare loss from purchasing such insurance.

The negative value of the mean utility premium is anticipated from convexity of utility over losses. Around three quarters of the uninsured display such preferences and so the same proportion have a negative utility premium (Table 6, Figure 5b). If there were no distortion in transforming subjective probabilities into decision weights and if there were no influences on demand other than risk perceptions and preferences, then, on average, these respondents would need to be offered a discount of 400 pesos on their perceived fair prices in order to persuade them to insure despite the convexity of their utility.

${ }^{30} \pi^{u}+\pi^{w}=W T P_{u}-\mu^{s}+W T P_{P T}-W T P_{u}=W T P_{P T}-\mu^{s}$ 
However, the distribution of the utility premium is highly skewed to the left. The median household would require a discount of only 39 pesos.

The negative mean weighting premium is more surprising. With PT, the motivation for insurance is anticipated to arise from overweighting the small probability of a loss (Wakker et al 1997). However, we find that the average uninsured respondent does not distort probabilities in forming decision weights (mean $\alpha=0.993$, median $\alpha=1$ ). In fact, around 45 percent use probabilities without distortion, as assumed in EU (see online Appendix 7, Figure A7.1 \& Table A7.1). As a result, the weighting premium is zero from the first to the third quartile of its distribution. The mean is negative because the nonlinear weighting that occurs in both directions do not cancel out and result in a leftskewed distribution of the weighting premium (Figure 5c). About 35 percent of the uninsured overweight small probabilities, while about a fifth underweight them (Appendix 7, Figure A7.1). As noted in section 2, with a continuous loss, there is a small probability of an unusually low value occurring, but there is also a small probability of a high value occurring. Hence, those who overweight small probabilities do not necessarily have greater WTP for insurance. Apparently, over the sample of uninsured households, probabilities associated with large medical expenditures are underweighted to an extent sufficient to reduce the mean WTP for insurance that would cover those expenses. If nothing other than probability weighting influenced the demand for insurance, then, on average, the uninsured would need to be offered a discount of almost 300 pesos on the actuarially fair price in order to be persuaded to purchase full insurance. However, more than four fifths would not require such a discount (Figure 5c). Probability weighting does not explain why most of the uninsured decide not to insure. But neither does it provide a strong motivation toward insurance.

The columns headed "weighting then utility" in Table 6 show utility and weighting premiums calculated following the alternative order of decomposition, i.e., first applying nonlinear probability weighting to linear utility to obtain the weighting premium, and then introducing nonlinear utility to find the effect of utility curvature. The medians of the two premiums are highly robust to the order of the decomposition. The means are less so. Calculating the utility premium after the weighting premium almost doubles the magnitude of its mean. With this approach, utility curvature appears to contribute even more to low WTP, on average. The mean of the weighting premium turns slightly positive when it is calculated before the utility premium, i.e. on the basis of linear utility. ${ }^{31}$ The estimates obtained from the first decomposition presented may therefore overstate the contribution of probability weighting to the low demand for insurance and understate that of utility convexity. Taking simple averages of the estimates obtained from the two decompositions gives mean utility and weighting premiums of -577 and -116 respectively. The robust finding is that, on average, risk attitudes drive down WTP for

${ }^{31}$ It sems that when a premium is calculated second, its distribution is more left-skewed and this pulls down the mean. 
insurance mainly due to convex utility over losses that is either compounded by distorted decision weights, or not sufficiently offset by them. The order of decomposition does not change the combined contributions of the two preference-related premiums and it has little or no effect on the medians of each of them.

The difference between the WTP derived from beliefs and risk attitudes consistent with PT $\left(W T P_{P T}\right)$ and the stated WTP $\left(W T P_{R}\right)$ is the residual, which absorbs determinants of $W T P_{R}$ that are not captured by the model. The mean of this residual is negative and quite large in magnitude. ${ }^{32}$ It reduces mean stated WTP by just over half as much as the reduction brought about by risk attitude. Besides risk perception and attitude, other factors clearly push the mean WTP for insurance below the fair price. However, the distribution of the residual is highly dispersed - the standard deviation is about ten times the magnitude of the mean - and left-skewed. The residual is positive at the median and for about three fifths of the uninsured respondents (Table 6, Figure 5d). We discuss factors that may contribute to the residual in section 7.1. For now, we note that the large magnitude of the mean residual is not unusual for decomposition methods, such as the extremely popular group-mean-difference decomposition of Oaxaca (1973) - Blinder (1973), that typically produce very large unexplained components. Nor does it signal a failure to provide insight. No model explains all systematic behavior, and any attempt to account for the low observed WTP for insurance with an EU model would produce an even larger residual.

\subsection{Decomposition of WTP for supplementary insurance}

The insured were asked to state their WTP for insurance covering all medical expenditures to be incurred in the next year. We interpret the response as the valuation of supplementary insurance. They were also asked to report probabilities of incurring non-reimbursed medical expenses in four intervals in the coming year and to identify the interval in which their non-reimbursed expense $\mathrm{s}$ fell in the last year. ${ }^{33}$ Together with the elicited risk attitudes, this information allows us to decompose the WTP for supplementary insurance.

The first two rows of Table 7 show estimates for all insured households. The first row reveals that the model-predicted mean WTP for supplementary insurance is 468 pesos less than the price that is fair for the average risk over all insured households. ${ }^{34}$ The median derived WTP falls even further

\footnotetext{
${ }^{32}$ The residual is unaffected by the order of obtained the contributions of utility curvature and probability weighting.

${ }^{33}$ Insured households pay OOP for healthcare because insurance is incomplete in both the services covered and the expenses reimbursed. In particular, providers can, and do, charge in excess of reimbursement ceilings (Capuno et al 2016).

${ }^{34}$ We exclude 51 respondents who report not knowing whether they are insured from Table 7. For further detail of the distributions of WTP and the components of the decomposition (beyond the mean and median) for all insured households see online Appendix 7, Table A7.2.
} 
short (by 2489 pesos) of this price. According to the model, most would not purchase supplementary insurance priced consistent with the average risk over all insured households. However, this is a highly heterogeneous pool encompassing those with mandatory coverage through formal sector employment but also the poor provided with fully subsidized insurance. Comparing the mean model-derived WTP within each insurance category with the fair price specific to that group reveals that the former is clearly smaller than the latter only for those with mandatory insurance and fully subsidized sponsored insurance due to some disadvantaged status (see lower rows of Table 7). For those who qualify for the indigent program and who insure voluntarily, the model-derived valuation is close to the respective fair price of insurance. But even in these two groups, the median $W_{T P} P_{P T}$ is below the group-specific fair price. So, irrespective of the type of insurance held, the model predicts that most would not demand supplementary insurance that was fairly priced for the respective risk pool. ${ }^{35}$

The predicted low demand for supplementary insurance is not due to optimism bias. Across all insured households, the mean and the median belief premiums are positive and substantially greater than those for the uninsured. ${ }^{36}$ On average, the insured expect to incur OOP payments of 3514 pesos but they spent 309 pesos less than that in the last year. The average subjective expectation is greater than the objective expectation. If the insured respondents were risk neutral, then, motivated only by their expectations, on average, they would purchase supplementary insurance that is priced fairly for the average (insurance group specific) risk, if this were available. The discrepancy between the perceived fair price and the fair price for the average risk results from pessimism about the likelihood of incurring high levels of expenditure. This is despite the insured being optimistically biased when comparing their own risk with the average. ${ }^{37}$ In relative terms, there is a tendency to perceive oneself as being a lower risk than others. But in absolute terms, there is overestimation of the level of risk faced, on average. This may be because the cover delivered by current insurance is not fully appreciated.

There is substantial variation in beliefs about future OOP spending not covered by insurance. Across all the insured, while the mean and median belief premiums are positive, more than two fifths have a subjective expectation that is less than the objective expectation across households with the same type of insurance cover (see online Appendix 7, Figure A7.2a). Downwardly biased risk perceptions could contribute to low demand for supplementary insurance for a substantial fraction of the insured.

\footnotetext{
${ }^{35}$ Bearing in mind that our estimate of WTP for supplementary insurance could be upwardly biased if the respondents reports their valuations of insurance covering currently reimbursed expenses, the estimates may well understate the strength of this prediction.

${ }^{36}$ The belief premium is calculated as the difference between a respondent's subjective expectation of (nonreimbursed) medical expenses and the mean of those expenses incurred by all households with the same type of insurance.

${ }^{37}$ As in the full sample (Table 1), the proportion (32\%) that assesses their likelihood of incurring medical expenses in excess of 8000 pesos as being smaller than that of similar households is greater than the proportion $(18 \%)$ that assess their likelihood as being larger.
} 
The mean belief premium is largest for the voluntarily insured and indigents. As a result, the model-derived WTP is closest to the fair price for these two groups. The extent to which the mean subjective expectation exceeds the objective expectation across those in the voluntary program suggests that pessimism may contribute to their decision to enroll. However, they do have good reason to insure. Even after doing so, on average, they still spend 177 pesos more OOP than the uninsured.

In aggregate and for each insurance group separately, despite a positive average belief premium, the mean and median stated WTP are both always substantially less than the respective fair price for supplementary insurance. According to stated preferences, and not only the model-derived WTP, the average insured household would not be interested in fairly priced (for the group-specific average risk) supplementary cover that fully protected them from gaps in their current cover. Negative influences on demand arising from risk attitudes and non-modelled factors more than offset the positive (average) belief premium.

Across all insured households, the two dimensions of risk attitude contribute approximately equally to the low mean WTP for supplementary insurance (Table 7, top row). ${ }^{38}$ Both contributions are highly left-skewed (see online Appendix 7, Figures A7.2b \& A7.2c). The median of each of the risk attitude premiums is close to zero. The weighting premium is negative for only about one fifth of insured households and is zero for more than half of them. These results suggest that for most of the currently insured, risk attitudes do not strongly influence their valuation of supplementary insurance and would not drive demand for this product. The residual is also left-skewed (online Appendix 7, Figure A7.2). While the mean is negative, the median is positive. A little more than half of the insured respondents state a WTP greater than the valuation derived from feeding their risk perceptions and preferences into the PT model. The largest mean residuals (in magnitude) are for the poor and the disadvantaged with fully subsidized cover provided through the indigent and sponsored programs respectively. One possible explanation is that poor and disadvantaged respondents are cognizant of their tight budget constraint when reporting their WTP for insurance but pay less attention to it when forecasting their future spending on healthcare. Another possibility is that the poor feel entitled to the fully subsidized insurance they have and report a low willingness to pay (relative to their forecast expenditure) as a statement of that entitlement, or possibly as a strategy to maintain the subsidy.

\footnotetext{
${ }^{38}$ Table 7 shows utility and weighting premiums obtained from the decomposition that first identifies the contribution of utility curvature and then finds that of probability weighting. Using the opposite order of decomposition, the mean utility premium is -791 and the mean weighting premium is -59 (see Appendix 7 , Table A7.3). As with the uninsured, this alternative decomposition increases the extent to which the low WTP for insurance is explained by convex utility over losses and reduces the extent to which it is explained by probability weighting. Also as for the uninsured, the median utility and weighting premiums are highly robust to the order of decomposition.
} 
Table 7: Decomposition of willingness to pay for supplementary insurance by type of insurance

\begin{tabular}{|c|c|c|c|c|c|c|c|}
\hline & \multirow{2}{*}{$\begin{array}{c}\text { Derived } \\
W T P_{P T}\end{array}$} & \multirow{2}{*}{$\begin{array}{l}\text { Stated } \\
W T P_{R}\end{array}$} & \multirow{2}{*}{$\begin{array}{l}\text { Fair price } \\
\qquad(\mu)\end{array}$} & \multicolumn{4}{|c|}{ Premium } \\
\hline & & & & $\begin{array}{c}\text { belief } \\
\left(\pi^{\mathrm{b}}\right)\end{array}$ & $\begin{array}{c}\text { utility } \\
\left(\pi^{\mathrm{u}}\right)\end{array}$ & $\begin{array}{c}\text { weighting } \\
\left(\pi^{\mathrm{w}}\right)\end{array}$ & $\begin{array}{c}\text { residual } \\
\left(\pi^{\varepsilon}\right)\end{array}$ \\
\hline \multicolumn{8}{|c|}{ All insured $(\mathrm{N}=969)$} \\
\hline Mean & 2735 & 2066 & 3202 & 309 & -382 & -395 & -669 \\
\hline Median & 714 & 1200 & 576 & 219 & -40 & 0 & 416 \\
\hline \multicolumn{8}{|c|}{ Mandatory $(\mathrm{N}=304)$} \\
\hline Mean & 2607 & 2151 & 3201 & 56 & -356 & -295 & -455 \\
\hline Median & 311 & 1,200 & 3201 & -11 & -39 & 0 & 1,128 \\
\hline \multicolumn{8}{|c|}{ Sponsored $(\mathrm{N}=177)$} \\
\hline Mean & 3338 & 1966 & 3944 & 222 & -266 & -561 & -1372 \\
\hline Median & 3630 & 1200 & 3944 & 347 & -32 & 0 & -616 \\
\hline \multicolumn{8}{|c|}{ Indigent $(\mathrm{N}=230)$} \\
\hline Mean & 2395 & 1670 & 2304 & 852 & -389 & -372 & -725 \\
\hline Median & 80 & 1200 & 2304 & 271 & -39 & 0 & 311 \\
\hline \multicolumn{8}{|c|}{ Voluntary $(\mathrm{N}=135)$} \\
\hline Mean & 3223 & 2818 & 3263 & 803 & -346 & -496 & -405 \\
\hline Median & 2824 & 2400 & 3263 & 758 & -33 & 0 & 828 \\
\hline \multicolumn{8}{|c|}{ Other $(\mathrm{N}=124)$} \\
\hline Mean & 2282 & 1912 & 3753 & -495 & -641 & -336 & -369 \\
\hline Median & 118 & 1200 & 3753 & -728 & -74 & 0 & 1083 \\
\hline
\end{tabular}

Notes: Table excludes respondents who report they are not insured $(\mathrm{N}=545)$ or do not know whether they are insured $(\mathrm{N}=51)$. Derived $W_{T P} P_{P}$ is obtained from Eq. 4 using the subjective distribution of medical expenses and elicited risk attitudes. Fair price is the insurance group (mandatory, sponsored, indigent, voluntary and other) specific mean of past expenditures. In the top two rows, it is the average of these means weighted by group sizes. Columns under heading 'Premium' give the components of the decomposition (Eq. 5). The belief premium is the difference between a respondent's subjective expectation and the mean past expenditure across all households in the same insurance group.

\section{Discussion}

\subsection{Interpretation}

Motivated by the puzzle of low demand for insurance, our focus is on the WTP of the uninsured. However, insight into the reasons some choose to insure while others do not can also be gained by comparing the decomposition results for the voluntarily insured with those for the uninsured. These groups do not differ much with respect to the two risk attitude contributions to WTP. It does not appear to be risk seeking preferences that are decisive in leading some to forgo the opportunity to insure while others grasp it. Rather, it is in expected medical expenditures that the uninsured differ most from the voluntarily insured. Objectively, the average expenses incurred by the uninsured are $5.4 \%$ below the average expenses of the voluntarily insured. Allowing for the fact that the latter have additional expenses that are reimbursed by their insurance, this suggests that there is adverse selection in voluntary enrollment. There is an even larger difference in the risk perceptions. The voluntarily insured overestimate their medical expenses by $25 \%$, on average. ${ }^{39}$ Both adverse selection and distorted beliefs seem to contribute to the decision to insure. In contrast, on average, the uninsured have close to unbiased expectations. Not only do the uninsured face lower risks, they seem to be aware of this.

\footnotetext{
${ }^{39}$ This does not explain their decision to insure because their stated beliefs concern OOP medical expenses not covered by the insurance they have chosen to purchase.
} 
Our PT-based decomposition identifies the contributions of risk perceptions and risk attitudes to the valuation of insurance. Unlike the EU model, it allows preferences to contribute to the low demand for insurance, leaving less to be attributed to extraneous factors. However, in common with decompositions that are widely used to explain differences in wages and many other economic outcomes (Fortin et al, 2011), it certainly does not explain all of the variation in the outcome, which in this case is WTP for insurance. There remains a large residual representing demand influences other than elicited risk perceptions and PT risk attitudes. Among the uninsured, the mean residual is negative, reducing WTP, and it is about half the magnitude of the contribution of preferences. It is useful to establish that model-extraneous factors contribute half as much to the deficit of WTP from the fair price as do convex utility and distorted decision weights. This tells us how much further insight could potentially be gained by enriching the model, and data collection, to allow for other determinants of insurance demand, while alerting us to the cost of sacrificing components of the current model that may be necessary in order to incorporate other explanations.

Many factors may contribute to the residual. One is the opportunity to self insure. In a multiperiod EU model, a household holding a sufficient buffer stock of wealth that is not liquidity constrained will prefer to self insure rather than purchase formal insurance offered at an actuarially unfair premium (Gollier 2003). Consumption can be maintained while spending on healthcare by drawing down savings and/or borrowing. Consumption can also be shielded from medical expenses by using informal interhousehold transfers to pool risks within a community or extended family (Cochrane 1990; Townsend 1994). Opportunities to self insure and to informally insure would be expected to reduce the (stated) WTP for formal insurance. Uninsured respondents with these options who take them into account when forming expectations will forecast greater future medical spending. In our model, this will raise the perceived fair price of insurance $\left(\mu^{s}\right)$. Medical expenditures financed in this way will also raise the objective fair price $(\mu)$ and so these alternatives to formal insurance have no effect on the belief premium $\left(\mu^{s}-\mu\right)$. Therefore, a reduction in $W T P_{R}$ relative to $\mu$ generated by self and informal insurance will push the residual in the negative direction. There is plenty evidence that self insurance and informal insurance are important sources of financing medical expenses in low- and middle-income countries (Townsend 1994; Gertler and Gruber 2002; Islam and Maitra 2012; Genoni 2012; Mohanan 2013; Liu 2016). It is plausible that this contributes to the low stated WTP and the large mean negative value of the residual.

As a form of self insurance, borrowing opportunities would be expected to reduce stated WTP and raise the magnitude of a negative residual. However, borrowing also offers a means of paying an insurance premium. Through this route, it could raise WTP. Demand for insurance has been found to be lower among liquidity constrained households (Giné et al 2008; Cole et al 2013; Liu and Myers 2016). With a binding liquidity constraint, the insurance and saving decisions are not entirely separable 
and stronger time preference is predicted to reduce WTP for insurance (Schlesinger and Zhang 2016; Van Wilgenburg et al 2018). Since this is not captured by the WTP derived from our single-period model, it will reduce the value residual; if it is negative (as it is, on average, in our sample), its magnitude will increase.

A lack of trust in insurance would also be expected to reduce $W T P_{R}$ and the value of residual term. The trustworthiness of insurance products has featured strongly in recent explanations of low demand for them in low-income settings (Giné et al 2008; Cole et al 2013; Cai et al 2015; Dercon et al 2015; Chemin 2018). It is potentially relevant in the context examined here since the health insurance offered in the Philippines carries a risk that a doctor charges in excess of the reimbursement ceiling set by the insurance agency. Effectively, there is a default risk that will reduce the perceived value of insurance (Doherty and Schlesinger 1990; Wakker et al 1997; Liu and Myers 2016). ${ }^{40}$ Uncertainty about whether the insurer will observe the conditions of the contract or vague specification of the contract, which is not uncommon with public and micro health insurance (Banerjee et al 2014), could have an impact on WTP by generating ambiguity. Ambiguity has been found to amplify probability weighting (Abdellaoui et al. 2011), yielding more pessimism and likelihood insensitivity. Additional pessimism would decrease WTP, while the effect of likelihood insensitivity, and so the overall effect, is unclear (see also Viscusi and Chelson, 1999). Finally, the residual term will absorb any (negative) effect on $W T P_{R}$ arising from lack of comprehension of how insurance works (Platteau 1997; Basaza et al 2008) and from any perception that the insurance only covers treatment from low quality doctors and facilities (De Allegri et al 2006; Basaza et al 2008).

While extending the model, data collection and decomposition to allow one or more of these additional influences on WTP to be separately identified would provide further insight into the demand for insurance, quantifying their collective contribution relative to those of risk perceptions and the two dimensions of risk attitude is already a useful exercise. It reveals the fraction of the deficit of WTP from the fair or subsidized price of insurance that is left unexplained and so indicates how valuable it would be to disaggregate further.

All of the potential contributors to the residual mentioned above would reduce stated WTP, pushing the residual in a negative direction. We find that the mean residual is indeed negative. However, there is much variation in the unexplained contributions. The residual is positive at the median and for

${ }^{40}$ An attraction of using PT with the reference point set to the no insurance-no loss state is that this model, unlike EU, captures the observed reluctance to purchase insurance that has a non-zero probability of not paying out (Wakker et al 1997). Under EU, the WTP for such insurance is predicted to fall in proportion to the default risk, while experimental evidence shows that it falls much more steeply (ibid). Papers that have examined the role of trust in the demand for health insurance in low-income settings (Dercon et al 2015; Chemin 2018) have adopted EU, and so allow default risk to impact on WTP only to a limited extent. If one were to elicit perceptions of the default risk, then our decomposition could easily be extended to identify the impact of trust on WTP following Wakker et al (1997). In the present decomposition, it will be captured by the residual if it influences $W T P_{R}$. 
most of the sample of uninsured respondents. There are two possible explanations. One is measurement error. There will be a lot of noise in the stated WTP and the elicited risk perceptions and preferences. Incentivizing tasks may have reduced noise. But the time and budget constraints faced in a large, general population field survey limit the scope for incentives. And it would have been extremely difficult to incentivize reporting of perceptions of a personal risk, like medical expenses. Another possible reason for the variation in the residual is that the PT model is not an adequate description of how some respondents value insurance. For example, for those who do so in accordance with maximization of concave utility defined over final wealth (EU), our model will under predict WTP if the same individuals display convex utility over losses. However, adopting EU would not help explain the observed low demand for insurance given the existence of substantial risk that is perceived with reasonable accuracy and so would raise the magnitude of the average residual.

\subsection{Limitations}

We decompose WTP using beliefs modelled as subjective probabilities and preferences consistent with PT. Compared with relying on the assumptions that the cross-sectional distribution provides an adequate approximation to the perceived distributions used by individuals and that EU is a descriptively accurate model of decision making, we believe our approach has advantages and that these are evident from its partial success in explaining the low WTP for health insurance. However, we do not have evidence that the people in our sample behave in accordance with PT.

The model relies on the assumption that the state with no insurance and no loss provides the appropriate reference point for the decision to insure. This is consistent with the standard application of PT to insurance (Wakker et al 1997). However, other reference points have been suggested for modelling insurance decisions. One is the prospect itself, as in the reference-dependent model of Köszegi and Rabin (2006, 2007), which consists of two parts: i) utility from the level of consumption, as in EU, plus ii) gain-loss utility, as in PT but without probability weighting and with a stochastic reference point (the prospect). The gain-loss utility is computed by comparing each outcome of a prospect with all other outcomes. The whole model is equivalent to rank-dependent utility (RDU) with a quadratic weighting function (Masatlioglu and Raymond 2016). For the prospect $(p: x, y)$ that gives the outcome $x$ with probability $p$ and $y(<x)$ with $1-p$, the model gives $(p: x, y) \rightarrow\{w(p) u(x)+(1-w(p)) u(y)\}$, where $\mathrm{w}(p)=(\lambda-1) p^{2}+(2-\lambda) p$ and $\lambda$ is the loss aversion parameter. In this model, the loss averse $(\lambda>1)$ act as if they have a convex weighting function, which generates more risk aversion. Köszegi and Rabin's model would therefore increase WTP for insurance in two ways: first, through the utility function that is typically assumed to be linear or concave (it is EU, not PT); second, through loss aversion. As such, it would not help explain the low demand for insurance in low-income populations. 
It may be that prospective purchasers of insurance do not view payment of the premium as a loss (Sydnor 2010). However, changing this assumption would also bring in loss aversion, raising the model-predicted WTP for insurance and so not leading to greater success in explaining the low stated WTP.

To conduct the decomposition of WTP, we had to assume specific forms for the value and weighting functions. While there is evidence to support those adopted (power utility and Prelec's weighting function), most tests have been conducted in high-income, western countries, and usually with student samples. We must assume that the results generalize to a quite different setting.

Our computed WTP relied on several measurements (beliefs, utility, probability weighting), each possibly subject to noise. It is not surprising, therefore, to obtain relatively low cross-individual correlation between the indirectly derived and directly elicited WTP $(\rho=0.06, \mathrm{p}=0.015)$. The low correlation also arises from variation in the (stated) valuation of insurance due to time preferences, selfinsurance options, liquidity constraints and trust in insurance, etc. that the model does not capture. Nonetheless, it is reassuring that comparisons of WTP across of groups defined by insurance status and type of insurance give meaningful findings.

The extent to which we can use the analysis to explain insurance choices is limited by the fact that beliefs about future spending on healthcare were elicited after the purchase of insurance (for those in the voluntary program). In a context where there is ex ante elicitation of beliefs and preferences as well as ex post observation of who takes up an offer to insure, our decomposition could be used to explain variation in insurance behavior.

Harrison and $\mathrm{Ng}$ (2016) examine consistency between insurance choices and elicited preferences (but not beliefs) in a laboratory experiment. They derive the consumer surplus for multiple insurance offers under both EU and RDU based on elicited utility curvature and probability weighting parameters. Around half of the small sample of undergraduates display risk attitudes consistent with EU. Despite respondents being given the objective probability of incurring a loss, around half of the insurance choices result in negative consumer surplus: the decision to insure or not makes the respondent worse off according to their own preferences. We have moved the study of consistency between insurance choices and the value of insurance derived from a behavioral model (with elicited risk attitudes) from the lab to the field. Rather than using the model-derived WTP to evaluate the logic of small-stakes insurance choices made quickly in an experiment, we used it to interpret the presumably contemplated decision not to insure a major risk. We have added risk perceptions as an additional influence on the valuation, as well as a potential source of error in insurance decisions. Further, we compared the derived WTP with the stated WTP, which allows us to quantify the influence of factors not captured by the model. 
In our decomposition, we applied probability weighting to elicited (sometimes called 'judged') beliefs. The weighting function was elicited from lottery choices. This approach is in line with the twostage model of Tversky and Fox (1995). However, if individuals perceive their medical risk as ambiguous, there is no guarantee that the (risk) weighting function applies. Individuals may have a specific weighting function that reflects ambiguity attitudes for this source of uncertainty (Abdellaoui et al. 2011). Such source dependent weighting functions may deviate from the risk weighting function in terms of elevation and curvature. It is unclear what the overall effect would be on the weighting premium.

\section{Conclusion}

We have introduced a method to decompose the deviation of willingness to pay for insurance from its fair price into three behaviorally determined contributions that reflect risk perception and two components of risk attitude - utility curvature and probability weighting - plus a residual term that absorbs all determinants of WTP that are not captured by our single-period prospect theory model. The motivation for this decomposition comes from the discrepancy that exists between low revealed WTP for insurance and the substantial risk that exists in low-income populations. We have applied the method to health insurance and it could also be used to explain the low demand for farming and weather insurance that is often observed in low- and middle-income countries.

We implemented the decomposition in the Philippines by collecting data on beliefs about future medical spending, actual medical expenditure and elicited risk attitudes that are unique in the context of a nationwide survey. The average WTP of uninsured households in the sample is only about two thirds of the fair price of insurance and it is less than the subsidized price at which public insurance is offered. This deficit is not explained by downwardly biased expectations of medical expenditures arising from optimism bias. Expectations of the uninsured are unbiased. The median subjective expectation is below the fair price but it is above the subsidized price at which insurance is offered. So, for most of the uninsured, inaccurate risk perceptions cannot explain their decision not to insure. Both convex utility in the domain of losses and the transformation of probabilities into decision weights push the mean WTP. Risk seeking characterized as convex utility in the domain of losses is widely observed and is consistent with PT. The more surprising result is that this is not offset by probability weighting to generate a demand for insurance, on average. However, both dimensions of risk attitude make skewed contributions to WTP. The median contribution of utility curvature is only slightly negative, while probability weighting does not contribute at all at the median. For many of the uninsured, risk attitude and perception are not sufficient to explain their decision not to insure. Other factors depress demand and our decomposition makes clear that their quantitative contribution is substantial. 


\section{References}

Abdellaoui, M., Baillon, A. Placido, L. \& Wakker, P.P. (2011). The rich domain of uncertainty: source functions and their experimental implementation, American Economic Review, 101(2), 699-727.

Acharya, A., Vellakkal, S., Taylor, F., Masset, E., Satija, A., \& Burke, M. (2013). The Impact of Health Insurance Schemes for the Informal Sector in Low- and Middle-Income Countries: A Systematic Review. World Bank Research Observer, 28(2), 236-266.

Attanasio, O. P. (2009). Expectations and perceptions in developing countries: their measurement and their use. The American Economic Review, 99(2), 87-92.

Banerjee, A., Duflo, E. and Hornbeck, R. (2014). Bundling Health Insurance and Microfinance in India: There Cannot Be Adverse Selection If There Is No Demand. American Economic Review: Papers and Proceedings, 104 (5), 291-97.

Barnes, K., Mukherji, A., Mullen, P., Sood, N., (2017). Financial risk protection from social health insurance. Journal of Health Economics 55, 14-29.

Basaza, R., Criel, B., \& Van der Stuyft, P. (2008). Community health insurance in Uganda: Why does enrollment remain low? A view from beneath. Health Policy, 87(2), 172-184.

Blinder, A. (1973). Wage discrimination: reduced form and structural estimates. Journal of Human Resources, 8, 436-55.

Bredenkamp, C., Evans, T., Lagrada, L., Langenbrunner, J., Nachuk, S., \& Palu, T. (2015). Emerging challenges in implementing universal health coverage in Asia. Social Science \& Medicine, $145,243-248$.

Bredenkamp, C., \& Buisman, L. R. (2016). Financial protection from health spending in the Philippines: policies and progress. Health Policy and Planning, 31(7), 919-927.

Bredenkamp, C., Capuno, J., Kraft, A., Poco, L., Quimbo, S., \& Tan Jr, C. A. (2017). Expansion of Health Insurance in the Philippines: Evidence from Panel Data. Health. Nutrition and Population Discussion Paper; World Bank, Washington, DC.

Bryan, G. (2018). Ambiguity Aversion Decreases Demand For Partial Insurance: Evidence from African Farmers. Journal of the European Economic Association forthcoming, https://www.dropbox.com/s/u9m70pc3vpazv6l/JEEA_Final.pdf?dl=0

Bundorf, M. K., \& Pauly, M. V. (2006). Is health insurance affordable for the uninsured? Journal of Health Economics, 25(4), 650-673.

Cai, H. Chen, Y., Fang, H. and Zhou, L.A. (2015). The effect of microinsurance on economic activities: evidence from a randomized field experiment. The Review of Economics and Statistics, May 2015, 97(2): 287-300

Cai, J. \& Song, C. (2017). Do Disaster Experiences and Knowledge Affect Insurance Take-up. Journal of Development Economics, 124, 83-94.

Capuno, J. J., Kraft, A. D., Quimbo, S., Jr. Tan, C. R., \& Wagstaff, A. (2016). Effects of price, information, and transactions cost interventions to raise voluntary enrollment in a social health insurance scheme: a randomized experiment in the Philippines. Health Economics, $25(6), 650-662$.

Casaburi, L. \& Willis, J. (2018). Time vs. state in insurance: Experimental evidence from contract farming in Kenya. American Economic Review forthcoming.

Charness, G., Gneezy, U., \& Imas, A. (2013). Experimental methods: Eliciting risk preferences. Journal of Economic Behavior \& Organization, 87, 43-51. 
Chemin, M. (2018). Informal Groups and Health Insurance Take-up Evidence from a Field Experiment. World Development 101, 54-72

Chernew, M., Frick, K., \& McLaughlin, C.G. (1997). The Demand for Health Insurance Coverage by Low-Income Workers: Can Re-duced Premiums Achieve Full Coverage? Health Services Research 32(4), 453-70.

Chuang, Y., \& Schechter, L. (2015). Stability of experimental and survey measures of risk, time, and social preferences: A review and some new results. Journal of Development Economics, 117, 151-170.

Cole, S., Giné, X., Tobacman, J., Topalova, P., Townsend, R. and Vickery, J. (2013). Barriers to Household Risk Management: Evidence from India. American Economic Journal: Applied Economics, 5(1): 104-35.

Cole, S., Stein, D. \& Tobacman, J. (2014). Dynamics of Demand for Index Insurance: Evidence from a Long-Run Field Experiment. American Economic Review Papers and Preceedings, 104 (5): 284-90.

Currie, J., \& J. Gruber. 1996. Health Insurance Eligibility, Utilization of Medical Care, and Child Health. Quarterly Journal of Economics 111(2), 431-66.

De Allegri, M., Sanon, M., Bridges, J., \& Sauerborn, R. (2006). Understanding consumers' preferences and decision to enroll in community-based health insurance in rural West Africa. Health Policy, 76(1), 58-71.

Delavande, A., Giné, X., \& McKenzie, D. (2011a). Measuring subjective expectations in developing countries: A critical review and new evidence. Journal of Development Economics, 94(2), 151-163.

Delavande, A., Giné, X., \& McKenzie, D. (2011b). Eliciting probabilistic expectations with visual aids in developing countries: how sensitive are answers to variations in elicitation design? Journal of Applied Econometrics, 26(3), 479-497.

Delavande, A. (2014). Probabilistic expectations in developing countries. Annual Review of Economics, 6(1), 1-20.

Dercon, S., Gunning, J.W. \& Zeitlin, A. (2015). The demand for insurance under limited trust: Evidence from a field experiment in Kenya. mimeo Georgetown University https://site.stanford.edu/sites/default/files/dgz_201503.pdf

Doherty, N. A., \& Schlesinger, H. (1990). Rational insurance purchasing: Consideration of contract nonperformance. Quarterly Journal of Economics, 105(1), 243-253.

Elabed, G., \& Carter, M. R. (2015). Compound-risk aversion, ambiguity and the willingness to pay for microinsurance. Journal of Economic Behavior \& Organization, 118, 150-166.

Finkelstein, A., Hendren, N., Luttmer, E.F.P., 2018. The Value of Medicaid: Interpreting Results from the Oregon Health Insurance Experiment. Journal of Political Economy forthcoming.

Fortin, N., Limieux, T. \& Firpo, S. (2011). Decomposition methods in economics. In O. Ashenfelter \& D. Card (Eds.), Handbook of Labor Economics, vol. 4, Part A, Chapter 1 pp. 1-102 . Amsterdam: Elsevier.

Genoni, M.E. (2012). Health Shocks and Consumption Smoothing: Evidence from Indonesia, Economic Development and Cultural Change 60(3), 475-506.

Gertler, P. and Gruber, J. (2002). Insuring Consumption Against Illness, American Economic Review 92(1), 51-70.

Giesbert, L., Steiner, S., \& Bendig, M. (2011). Participation in micro life insurance and the use of other financial services in Ghana. Journal of Risk and Insurance, 78(1), 7-35. 
Giné, X., Townsend, R. and Vickery, J.I. (2008). Patterns of Rainfall Insurance Participation in Rural India. World Bank Economic Review 22 (3), 539-66.

Gollier, C., (2003). To insure or not to insure? An insurance puzzle. The Geneva Papers on Risk and Insurance Theory, 28, 5-24.

Gross, T., Notowidigdo, M.J., 2011. Health insurance and the consumer bankruptcy decision: Evidence from expansions of Medicaid. Journal of Public Economics 95, 767-778.

Hilton, R. W. (1988). Risk attitude under two alternative theories of choice under risk. Journal of Economic Behavior \& Organization, 9(2), 119-136.

Islam, A. \& P. Maitra (2012). Health Shocks and Consumption Smoothing in Rural Households: Does Microcredit have a Role to Play? Journal of Development Economics, 97(2): 232-243.

Kahneman, D. \& Tversky, A. (1979). Prospect theory: An analysis of decision under risk. Econometrica, 47, 263-291.

Köszegi, B. \& Rabin, M. (2006). A Model of Reference-Dependent Preferences. Quarterly Journal of Economics, 121(4): 1133-1166

Köszegi, B. \& Rabin, M. (2007). Reference-Dependent Risk Attitudes. American Economic Review, 97(4): 1047-1073.

Levy, H. \& DeLeire, T. (2008/2009) What Do People Buy When They Don't Buy Health Insurance and What Does that Say about Why They Are Uninsured? Inquiry Winter 45(4): 365-379.

Lichtenstein, S., Fischhoff, B., \& Phillips, L. D. (1982). Calibration of subjective probabilities: The state of the art up to 1980. In D. Kahneman, P. Slovic, \& A. Tversky (Eds.), Judgment under uncertainty: Heuristics and biases (pp. 306-334). New York:Cambridge University Press.

Limwattananon, S., Neelsen, S., O'Donnell, O., Prakongsai, P., Tangcharoensathien, V., Van Doorslaer, E., \& Vongmongkol, V. (2015). Universal coverage with supply-side reform: The impact on medical expenditure risk and utilization in Thailand. Journal of Public Economics, $121,79-94$.

Liu, K. (2016). Insuring Against Health Shocks: Health Insurance and Household Choices, Journal of Health Economics 46, 16-32.

Liu, Y. \& Myers, R.J. (2016). The dynamics of microinsurance demand in developing countries under liquidity constraints and insurer default risk. Journal of Risk and Insurance, 83(1), 121-138.

Manski, C. F. (2004). Measuring expectations. Econometrica, 72(5), 1329-1376.

Masatlioglu, Y. \& Raymond, C. (2016). A Behavioral Analysis of Stochastic Reference Dependence. American Economic Review, 106(9): 2760-2782.

Mohanan, M. (2013). Causal Effects of Health Shocks on Consumption and Debt: QuasiExperimental Evidence from Bus Accident Injuries, Review of Economics and Statistics 95(2), 673-681.

Murphy, J. J., Allen, P. G., Stevens, T. H. \& Weatherhead, D. (2005). A Meta-Analysis of Hypothetical Bias in Stated Preference Valuation. Environmental and Resource Economics, 30(3), 313-325.

Novemsky, N. \& Kahneman, D. (2005). The Boundaries of Loss Aversion Journal of Marketing Research, 42(2), 119-128.

Oaxaca, R. (1973). Male-female wage differentials in urban labor markets. International Economic Review, 14, 693-709.

Pauly, M. V., Blavin, F. E., \& Meghan, S. (2009). How private, voluntary health insurance can work in developing countries. Health Affairs, 28(6), 1778-1787. 
Pettigrew, L. M., \& Mathauer, I. (2016). Voluntary Health Insurance expenditure in low- and middleincome countries: Exploring trends during 1995-2012 and policy implications for progress towards universal health coverage. International Journal for Equity in Health, 15(1), 67. doi:10.1186/s12939-016-0353-5

Platteau, J.-P. (1997). Mutual insurance as an elusive concept in traditional rural communities. Journal of Development Studies, 33(6),764-796.

Platteau, J.-P., De Bock, O. \& Gelade, W. (2017). The demand for microinsurance: a literature review. World Development 94, 139-156.

Prelec, D. (1998). The probability weighting function. Econometrica, 66, 497-527.

Schlesinger, H. \& Zhuang, B. (2016). Protection against Future Risk: a Two-Period Model for Insurance and Saving/Borrowing. Mimeo University of Alabama.

Shigeioka, H., 2014. The effect of patient cost sharing on utilization, health, and risk protection. American Economic Review 104, 2152-2184.

Stott, H. P. (2006). Cumulative prospect theory's functional menagerie. Journal of Risk and uncertainty, 32(2), 101-130.

Sydnor, J. (2010). (Over) insuring modest risks. American Economic Journal: Applied Economics, 2(4), 177-199.

Townsend, R.M. (1994). Risk and Insurance in Village India, Econometrica, 62(3), 539-591.

Tversky, A., \& Fox, C. R. (1995). Weighing risk and uncertainty. Psychological Review, 102(2), 269.

Tversky, A., \& Kahneman, D. (1992). Advances in prospect theory: Cumulative representation of uncertainty. Journal of Risk and Uncertainty, 5(4), 297-323.

Van Doorslaer, E., O'Donnell, O., Rannan-Eliya, R. P., Somanathan, A., Adhikari, S. R., Garg, C. C., Harbianto, D., Herrin, A.N., Huq, M.N., Ibragimova, S. \& Karan, A (2007). Catastrophic payments for health care in Asia. Health Economics, 16(11), 1159-1184.

Van Wilgenburg, K., Baillon, A., O’Donnell, O. \& Quimbo, S. (2018). Do (non-standard) risk and time preferences explain health insurance enrollment? mimeo Erasmus University Rotterdam.

Viscusi, W.K. \& Chesson, H.W. (1999). Hopes and Fears: The Conflicting Effects of Risk Ambiguity, Theory and Decision 47, 153-178.

Wagstaff, A., Nguyen, H. T. H., Dao, H., \& Bales, S. (2016). Encouraging health insurance for the informal sector: a cluster randomized experiment in Vietnam. Health Economics, 25(6), 663674.

Wakker, P., Thaler, R., \& Tversky, A. (1997). Probabilistic insurance. Journal of Risk and Uncertainty, 15(1), 7-28.

Wakker, P. P. (2010). Prospect theory: For risk and ambiguity. Cambridge University Press: Cambridge.

Weinstein, N. D. (1980). Unrealistic optimism about future life events. Journal of Personality and Social Psychology, 39(5), 806.

Weinstein, N. D., \& Klein, W. M. (1996). Unrealistic optimism: Present and future. Journal of Social and Clinical Psychology, 15(1), 1-8.

Yilma, Z., O'Donnell, O., Mebratie, A., Alemu, G., \& Bedi, A. S. (2018). Subjective Expectations of Medical Expenditures and Insurance in Rural Ethiopia. In B. Baltagi and F. Moscone (eds.) Contributions to Economic Analysis Vol. 294: Health Econometrics, pp. 23-56. Emerald Publishing: Bingley. 